'Department of Medicine, University of Alberta, Edmonton, Alberta, Canada ${ }^{2}$ Centre for Kidney Disease Research, University of Queensland, Brisbane, Queensland, Australia.

${ }^{3}$ Department of Renal Medicine, Singapore General Hospital, Singapore, Singapore.

${ }^{4}$ Ceorge Institute for Global Health, UNSW, New Delhi, India.

${ }^{5}$ Australasian Kidney Trials Network, University of Queensland, Brisbane, Queensland, Australia. 凶e-mail:david.johnson2@ health.qld.gov.au

\title{
Epidemiology of haemodialysis outcomes

\begin{abstract}
Aminu K. Bello ${ }^{1}$, Ikechi G. Okpechi', Mohamed A. Osman ${ }^{1}$, Yeoungjee Cho ${ }^{2}$, Htay Htay3, Vivekanand Jha $\mathbb{D}^{4}$, Marina Wainstein (iD) ${ }^{2}$ and David W. Johnson (1) ${ }^{2,5 凶}$
\end{abstract} \\ Abstract | Haemodialysis (HD) is the commonest form of kidney replacement therapy in the world, accounting for approximately $69 \%$ of all kidney replacement therapy and $89 \%$ of all dialysis. Over the last six decades since the inception of HD, dialysis technology and patient access to the therapy have advanced considerably, particularly in high-income countries. However, HD availability, accessibility, cost and outcomes vary widely across the world and, overall, the rates of impaired quality of life, morbidity and mortality are high. Cardiovascular disease affects more than two-thirds of people receiving $\mathrm{HD}$, is the major cause of morbidity and accounts for almost $50 \%$ of mortality. In addition, patients on $\mathrm{HD}$ have high symptom loads and are often under considerable financial strain. Despite the many advances in $\mathrm{HD}$ technology and delivery systems that have been achieved since the treatment was first developed, poor outcomes among patients receiving HD remain a major public health concern. Understanding the epidemiology of HD outcomes, why they might vary across different populations and how they might be improved is therefore crucial, although this goal is hampered by the considerable heterogeneity in the monitoring and reporting of these outcomes across settings.
}

Chronic kidney disease (CKD) is a growing, global public health priority that is associated with markedly high morbidity, mortality and excess health-care costs ${ }^{1-4}$. In 2017, a total of 850 million people were estimated to be living with CKD, which was twice the estimated prevalence of diabetes worldwide and over 20 times the estimated global prevalence of HIV or AIDS ${ }^{5}$. Although global age-standardized mortality for most other forms of chronic disease (such as cardiovascular disease (CVD) and cancer) has decreased over the past few decades, $\mathrm{CKD}$ is the third fastest growing cause of death globally and is projected to become the fifth commonest cause of years of life lost by 2040 (REFS ${ }^{6,7}$ ).

As CKD progresses from its early stages to kidney failure (defined as an estimated glomerular filtration rate (eGFR) $<15 \mathrm{ml} / \mathrm{min} / 1.73 \mathrm{~m}^{2}$ or treatment by dialysis ${ }^{8,9}$ ), morbidity, mortality and health-care costs rise rapidly and life expectancy is dramatically reduced unless kidney replacement therapy (KRT) is initiated ${ }^{10}$. In 2017, estimates indicated that 3.9 million persons with kidney failure were treated with KRT globally; ; notably, an approximately equivalent number of patients with kidney failure did not receive $\mathrm{KRT}^{11}$. Haemodialysis (HD) is the commonest form of KRT in the world, accounting for approximately $69 \%$ of all KRT and $89 \%$ of all dialysis ${ }^{10,12,13}$. According to a 2018 cross-sectional survey of clinicians, policy makers and patient representatives in 182 countries, the median country-specific use of HD was 298.4 per million population (pmp) but varied over 7,000-fold between countries, ranging from $0.3 \mathrm{pmp}$ in the Democratic Republic of Congo to 2,148 pmp in Japan, owing to variable HD availability and access $^{14}$.

Reported outcomes for patients treated with HD are similarly variable around the world, although morbidity and mortality rates are high overall ${ }^{15,16}$. Achieving better HD outcomes through continuous quality improvement is constrained by the limited monitoring and reporting of quality outcomes, the use of variable outcome definitions that prevent benchmarking and data comparison, the lack of a framework for minimum and optimal safety and quality standards for $\mathrm{HD}$, and variable practices and gaps in kidney failure care (including shortfalls in the health workforce, access to medicines, dialysis service delivery, health information systems, financing, and leadership or governance) $)^{13,14,17-21}$.

In this Review, we describe the contemporary epidemiology of centre-based HD outcomes, including clinical, patient-reported, and surrogate outcomes. We highlight the need to identify and standardize HD outcomes that are important to patients and clinicians, and the variability reported in a large number of clinical, patient-reported and surrogate outcomes across populations and world regions. Further, we examine the HD outcomes observed in vulnerable populations (including female patients, older individuals, children, 


\section{Key points}

- Nearly 4 million people in the world are living on kidney replacement therapy (KRT), and haemodialysis (HD) remains the commonest form of KRT, accounting for approximately $69 \%$ of all KRT and $89 \%$ of all dialysis.

- Dialysis technology and patient access to KRT have advanced substantially since the 1960s, particularly in high-income countries. However, HD availability, accessibility, cost and outcomes continue to vary widely across countries, particularly among disadvantaged populations (including Indigenous peoples, women and people at the extremes of age).

- Cardiovascular disease affects over two-thirds of people receiving HD, is the major cause of morbidity and accounts for almost $50 \%$ of mortality; mortality among patients on $\mathrm{HD}$ is significantly higher than that of their counterparts in the general population, and treated kidney failure has a higher mortality than many types of cancer. Patients on HD also experience high burdens of symptoms, poor quality of life and financial difficulties.

- Careful monitoring of the outcomes of patients on HD is essential to develop effective strategies for risk reduction. Outcome measures are highly variable across regions, countries, centres and segments of the population. Establishing kidney registries that collect a variety of clinical and patient-reported outcomes using harmonized definitions is therefore crucial.

- Evaluation of HD outcomes should include the impact on family and friends, and personal finances, and should examine inequities in disadvantaged populations, who comprise a large proportion of the HD population.

and Indigenous peoples), and the current status of monitoring and reporting of HD outcomes across the globe. We also discuss potential mechanisms and strategies for improvement of various HD outcomes.

Identification and standardization of HD outcomes A major limitation to clinical research and quality reporting of outcomes in patients treated with HD has been a lack of use of standardized HD outcomes that are relevant to patients and their caregivers. In the past 4 years, considerable efforts have been made to identify key outcomes that are important to patients and should therefore be prioritized for monitoring, reporting and intervention in $\mathrm{HD}^{22}$. Using a two-phase, sequential exploratory mixed methods study design with focus groups and an online survey, the Kidney Health Initiative identified three physical symptoms (insomnia, fatigue and cramping) and three mood symptoms (anxiety, depression and frustration) in patients receiving HD that should be prioritized ${ }^{23}$. Moreover, the Standardized Outcomes in Nephrology in HD (SONG-HD) initiative conducted a five-phase mixed methods process including a Delphi survey involving 1,181 participants (220 patients and caregivers, and 979 health professionals) from 73 countries to identify four core outcome domains (fatigue, CVD, vascular access and mortality) that should be reported in all clinical trials in patients receiving $\mathrm{HD}^{22,24-29}$ (FIG. 1). Work is currently underway to develop validated core outcome measures for each of these domains ${ }^{26,27}$. Although this research effort is clearly focused on HD clinical trials, the findings have clear implications for clinical and patient-reported outcomes that should be monitored and reported in HD clinical practice.

\section{Clinical HD outcomes across the globe}

Clinical HD outcomes include key hard outcomes experienced by patients on HD during the trajectory of their treatment life course. Below we discuss patient mortality,
CVD burden, vascular access-related events, infections, hospitalization and cognitive impairment.

Mortality. Patients receiving HD have significantly higher mortality than their counterparts from the general population matched for age and sex (FIC. 2), and the mortality for treated kidney failure is higher than that of many types of cancer ${ }^{30}$. Several studies comparing $\mathrm{HD}$ and peritoneal dialysis (PD) reported survival benefits for $\mathrm{HD}^{31-33}$, but large-scale observational studies showed no significant difference between the two dialysis modalities. PD might be associated with a survival advantage in the first few years ${ }^{31}$. In the last 20 years, only two randomized controlled trials (RCTs) have compared HD and PD mortality outcomes. The China Q study ( $n=668)$ is expected to complete by 2022 , although preliminary findings have been reported ${ }^{34}$. The other RCT (NECOSAD study) was reported in 2003 and had a small cohort of 38 patients with a mean follow-up of 2.23 years. Researchers found a survival advantage in favour of PD compared with $\mathrm{HD}^{35}$, but the study was limited owing to poor generalizability, a highly selected trial population and premature termination due to recruitment difficulty. A combined analysis of both trials ${ }^{31}$ found that the relative risk of death on PD versus HD was 0.61 (95\% confidence interval (CI) 0.36-1.06); this risk difference was not significant but suggests that PD might have mortality benefits compared with HD. Given the lack of a substantial difference in survival outcome between $\mathrm{HD}$ and $\mathrm{PD}$, a patient-centred approach is recommended when selecting a dialysis modality, although local circumstances and availability must also be taken into account ${ }^{36}$.

Mortality is highest within the first 90 days after HD initiation. Using Dialysis Outcomes and Practice Patterns Study (DOPPS) data, a retrospective cohort study of 4,802 incident dialysis patients treated with HD in the USA showed an increased risk of death during the first 120 days compared with 121-365 days after initiation of $\mathrm{HD}$, particularly in those who had received kidney care from a nephrologist for less than 1 month prior to DOPPS enrolment ${ }^{37}$. Another DOPPS analysis of the mortality patterns in 86,886 patients in 11 countries (Australia, New Zealand, Belgium, Canada, France, Germany, Italy, Japan, Sweden, UK and USA) found that crude mortality (deaths per 100 patient-years) were 26.7 (range 17.0-33.5) in the early period ( $<120$ days), 16.9 (range 5.3-21.8) in the intermediate period (121-365 days) and 13.7 (range $5.2-19.9)$ in the late period (>365 days $)^{38}$. Thus, attempts to improve HD mortality outcomes should focus on the first few months of dialysis ${ }^{38}$.

Although the overall mortality in incident HD patients has been progressively improving in high-income countries (HICs) ${ }^{39,40}$, less is known about lower-middle-income countries (LMICs), where mortality data are much less likely to be recorded or reported ${ }^{41}$. Crude 1-year mortality among prevalent HD patients has been reported to be $6.6 \%$ in $\operatorname{Japan}^{42}, 15.6 \%$ in Europe ${ }^{42}$ and $21.7 \%$ in the $\mathrm{USA}^{42}$, whereas 1-year survival was $90 \%$ in Australia ${ }^{40}$, $89 \%$ in New Zealand ${ }^{40}, 65 \%$ in $\operatorname{Iran}^{43}, 95 \%$ in Morocco ${ }^{44}$, $90.4 \%$ in South Africa ${ }^{45}$ and $~ 38 \%$ in Peru ${ }^{46}$.

Efforts to improve HD mortality initially focused on dialysis adequacy ${ }^{47,48}$, although the HD (HEMO) 
RCT $(n=1,846)$ did not find that mortality was significantly altered by the use of a high-dose versus a standard dialysis dose, or a high versus low membrane flux $^{49}$. In patients with kidney failure, CVD remains the primary mortality driver and has become the focus of efforts to reduce mortality risk ${ }^{50}$.

Cardiovascular disease. CVD affects more than two-thirds of people receiving $\mathrm{HD}$, is the major cause of morbidity and accounts for almost $50 \%$ of mortality $^{51}$. CVD mortality data vary considerably across different regions ( $>50 \%$ of cases in the USA ${ }^{39}$ but only $21 \%$ of cases in Australia and New Zealand ${ }^{52}$ ). The range of CVD affecting people receiving HD is broad and extends from atherosclerosis-related complications, such as myocardial infarction and stroke, to heart failure, and non-fatal and fatal arrhythmias. Sudden cardiac death (SCD), defined as an unexpected death due to cardiac causes in a person within $1 \mathrm{~h}$ of symptom onset (witnessed) or within $24 \mathrm{~h}$ of the last proof of life (unwitnessed), is the most common cause of cardiovascular death in people receiving dialysis ${ }^{53}$. SCD is approximately $50 \%$ more common among people receiving $\mathrm{HD}$ than in those treated with $\mathrm{PD}^{54}$, possibly owing to the effect of intradialytic hypotension on cardiac perfusion and electrolyte flux-related arrhythmias ${ }^{55}$. The importance of these SCD risk factors that are unique to $\mathrm{HD}$ is supported by the observation that the incidence of cardiovascular death increases following long HD breaks (OR, 1.26; 95\% CI 1.14-1.40) ${ }^{56}$. International data from the DOPPS showed that SCD was most common in the USA (33\% of all deaths), followed by Japan (23\%), Australia and New Zealand (19\%) and Canada $(18 \%)^{57}$.

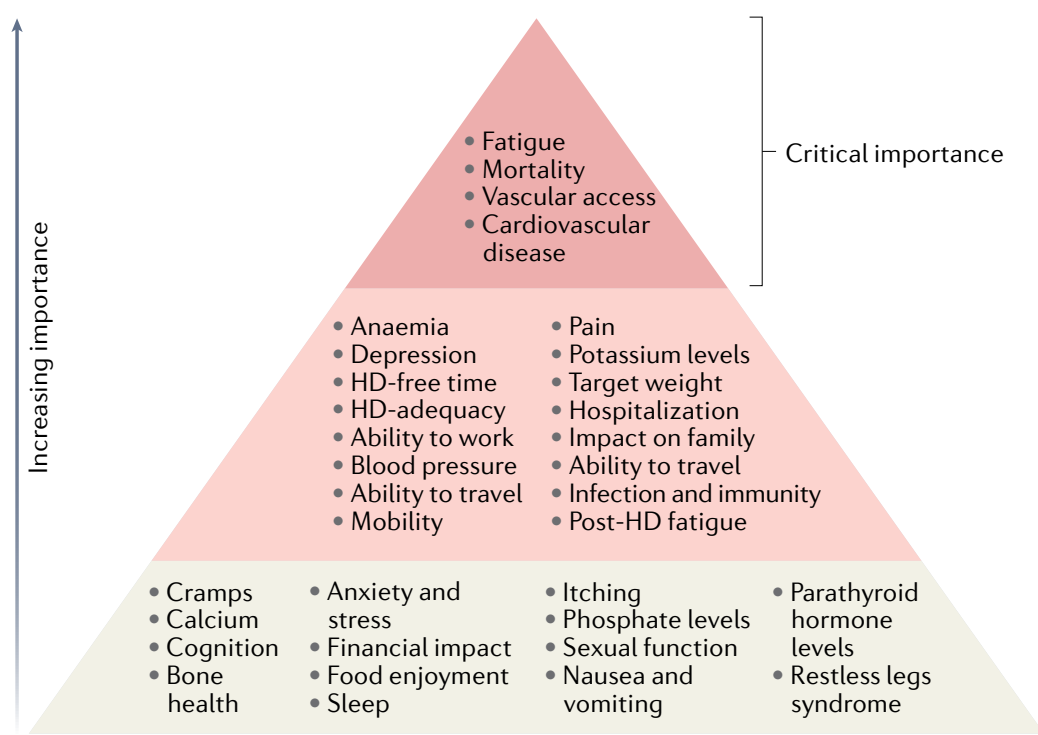

Fig. 1 | Hierarchy of importance of haemodialysis outcomes to patients, caregivers and clinicians. The Standardized Outcomes in Nephrology in Haemodialysis initiative has identified a hierarchy of HD outcomes according to their level of importance to stakeholder groups ${ }^{22,24-29}$. The outcomes in the top tier are critically important to all stakeholder groups, those in the middle tier are critically important to some stakeholder groups and those in the bottom tier are important to some or all stakeholder groups. Adapted with permission from Tong et al. ${ }^{263}$, Elsevier.
Of note, the degree of variation in CVD amongst people receiving $\mathrm{HD}$ across the globe remains uncertain owing to considerable heterogeneity in measurement and reporting. Outcomes related to CVD are often restricted to data obtained from HICs with a robust health information infrastructure (for example, the USA). In a global survey of kidney failure care, death was not monitored at all in 12 countries (8\%), which were predominantly low-income countries (LICs; $n=3)$ and LMICs $(n=7)^{14}$. Definitions of CVD are also markedly heterogeneous.

The disproportionately high incidence of CVD among patients with kidney failure is thought to be driven by an abundance of both traditional (for example, hypertension or diabetes) and non-traditional risk factors (for example, electrolyte imbalances or cardiac hypertrophy $)^{58}$. Interventions that target traditional risk factors such as blood pressure have not been shown to be effective and no 'optimal' targets exist ${ }^{59,60}$ to inform clinical decisions because people receiving HD are often excluded from clinical trials ${ }^{61-63}$. Similarly, effective treatments that target non-traditional risk factors (for example, uraemic toxin reduction) in people treated with $\mathrm{HD}$ are currently lacking.

In recognition of its prevalence, life-threatening consequences and lack of available effective interventions, CVD was identified as a core outcome by the SONG-HD initiative ${ }^{22,27}$ (FIG. 1). A systematic review of 175 trials reporting CVD in patients receiving HD identified a large heterogeneity in reporting with $>230$ measures used for 26 CVD outcomes including myocardial infarction, stroke and cardiac arrest ${ }^{27}$. A subsequent consensus workshop identified myocardial infarction and SCD as core outcome measures to capture CVD in all trials involving people receiving $\mathrm{HD}^{27}$. Comparison and benchmarking of accurate CVD data in both clinical trials and quality registries using harmonized definitions will help to better inform clinicians and patients regarding CVD burden and strategies to mitigate it.

Vascular access-related outcomes. Vascular accessrelated complications and interventions account for almost one-third of hospital admissions among patients receiving $\mathrm{HD}$, which creates an enormous burden for patients, caregivers ${ }^{64}$ and health-care ${ }^{65,66}$ systems. Compared with arteriovenous fistulas (AVF) and arteriovenous grafts (AVG), central venous catheters (CVC) are typically associated with the highest risks of all-cause mortality, fatal infections and $\mathrm{CVD}^{67}$. This association might be driven by infections caused by skin microbes that colonize catheters; such infections can lead to hospitalization, access failure and death ${ }^{68}$. However, these results might also represent indication bias with residual confounding. For example, the National Kidney Foundation Kidney Disease Outcomes Quality Initiative acknowledged CVC as an acceptable vascular access modality in patients with poor prognoses ${ }^{69}$ (for example, patients with heart failure) and CVCs might therefore be a surrogate marker of poor outcomes ${ }^{70}$. In addition, numerous patient-level (for example, presence of suitable vasculature) and centre-level characteristics (for example, infrastructure and programme culture regarding vascular access) can affect the type, location and timing of vascular access creation ${ }^{71}$. 


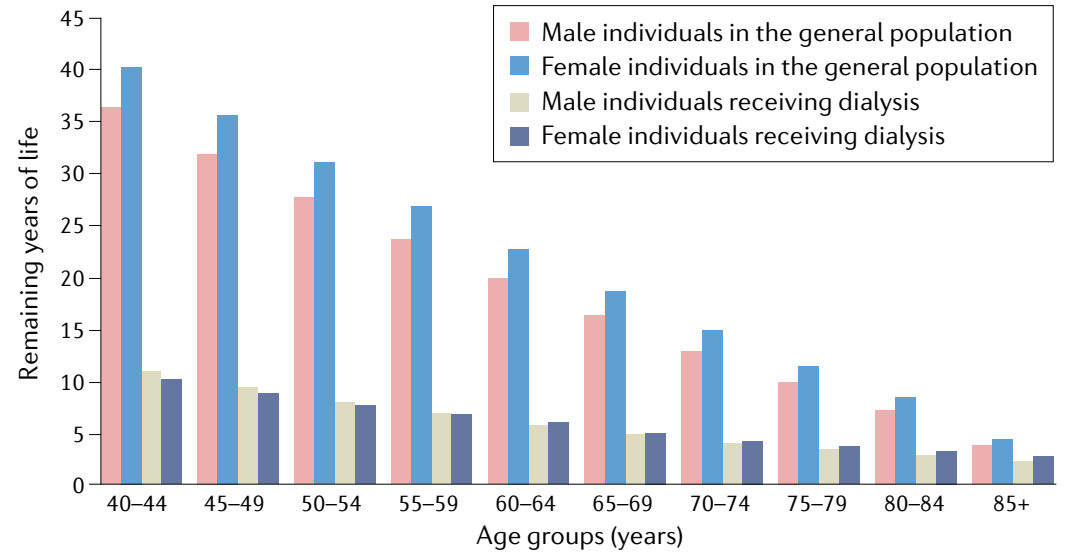

Fig. 2 | Expected remaining years of life in prevalent patients on dialysis. Expected remaining lifetime, in years, for the 2018 prevalent kidney failure population and the 2017 general population in the USA. The graph illustrates the markedly shortened projected lifespan for patients with kidney failure compared with that of individuals without kidney failure. In individuals aged 40-44 years, for example, the projected lifespan difference between men receiving dialysis (expectancy 10.9 years) and men in the general population (expectancy 36.5 years) is $>25$ years ( $>30$ years for women). Unsurprisingly, the difference in expected remaining years of life decreases with increasing age. However, even men and women aged $80-84$ years on dialysis have life expectancies that are 4.3 and 5.3 years shorter, respectively, than their counterparts who are not receiving dialysis. Graph is reprinted from United States Renal Data System ${ }^{39}$, CC BY 4.0 (https://creativecommons.org/licenses/by/4.0/).

Unfortunately, despite widespread recognition of poor outcomes and the availability of international guidelines to inform clinical practice ${ }^{72}, \mathrm{CVC}$ usage at $\mathrm{HD}$ commencement remains high (used in $>50 \%$ of patients in Australia and New Zealand and in $>80 \%$ of patients in the USA $)^{39,40}$ and has improved minimally over time. Almost half $(46 \%, n=69)$ of countries that responded to the International Society of Nephrology Global Kidney Health Atlas survey indicated that CVCs were used in most of their patients starting $\mathrm{HD}^{14}$; this practice was prevalent across World Bank Income groups - LICs, 34.8\%; LMICs, 54.1\%; upper-middle-income countries (UMICs), 51.4\%; HICs, $40.7 \%$.

Large variations in the type of vascular access used for HD can often be observed within the same country. A study from Australia and New Zealand that included 27,123 patients receiving HD from 61 centres $^{73}$ observed a 4 -fold variation in AVF and AVG use at initiation of HD across centres. Although no specific centre-level characteristics were associated with higher AVG or AVF use, adjustment for centre-level characteristics (for example, centre size, transplanting status and proportion of patients receiving home HD versus facility-based HD) reduced the observed inter-centre variability of arteriovenous access use at $\mathrm{HD}$ initiation by $25 \%$, which highlights the importance of centre practice patterns.

The locations and outcomes of AVFs are also varied. A prospective cohort study that used DOPPS data ( $n=3,850$ patients from 11 countries) reported that Japan had the highest percentage of lower arm AVF creation $(\geq 93 \%)$, compared with $65-77 \%$ in Europe, Australia and New Zealand, and $32 \%$ in the USA ${ }^{74}$. Notably, the proportion of lower arm AVFs decreased from $70 \%$ to $32 \%$ between 1996 and 2015 (data from five cross-sectional studies) in the USA, possibly in response to the 'Fistula First Initiative' and the Centres for Medicare and Medicaid Services Quality Incentive Program, which promoted upper arm AVF as more likely to be successful than lower arm $\mathrm{AVF}^{75}$. However, this practice should be approached cautiously as the creation of upper arm AVF limits the number of sites available for future vascular access and is associated with higher incidences of steal syndrome and cardiac dysfunction $^{76,77}$. Rates of successful AVF use (defined as $\geq 30$ days of continuous use) were $87 \%$ in Japan, $67 \%$ in Europe, Australia and New Zealand, and 64\% in the USA. Rates for AVGs were $86 \%, 75 \%$ and $78 \%$, respectively ${ }^{74}$.

Infection. Patients on HD are more susceptible to infection than the general population given their immunocompromised condition $^{78}$. Access-related bloodstream infections (ARBSIs) are one of the most common types of infection in patients receiving $\mathrm{HD}^{79}$. A study that included 6,005 HD centres in the USA reported that the ARBSI rate was 0.64 per 100 patient-months (2.16 for CVC, 0.26 for AVF and 0.39 for AVG) $)^{79}$. The risk of ARBSI was eight-fold higher with CVC use than with AVF, and increased with prolonged catheter use ${ }^{80}$. In other parts of the world, ARBSI rates have been reported at 0.4 per 100 patient-months in Saudi Arabia, 0.57 per 100 patient-months in Canada ${ }^{81}, 2.3$ per 100 patient-months in Singapore ${ }^{82}, 6.8$ per 100 patient-months in Germany ${ }^{83}$, 32.4 per 100 patient-months in Algeria and 34.2 per 100 patient-months in $\operatorname{Iran}^{84}$. Common causative organisms for ARBSI include Staphylococcus aureus, coagulase-negative staphylococcus, and enterococcus ${ }^{79}$. Compared with other bacteria, S. aureus bacteraemia was associated with higher rates of disseminated infection, including septic arthritis and endocarditis, and required a prolonged course of antibiotics. All indwelling vascular catheters are colonized by microorganisms within $24 \mathrm{~h}$ of insertion; ${ }^{85}$ these microorganisms proliferate to form biofilms and can subsequently spread into the bloodstream ${ }^{86}$. CVC avoidance (where practical and feasible) is the key to preventing ARBSI in patients receiving $\mathrm{HD}^{72,86}$. The use of a proper sterile technique during catheter placement and with each HD session is essential, and the prophylactic use of topical antibiotics and antimicrobial catheter locks, which have been shown to reduce the risk of ARBSIs (evidence strength was moderate to high), should be considered in patients with $\mathrm{HD}$ catheters ${ }^{72,86}$ (BOX 1).

Patients on HD are also at increased risk of bloodborne virus infections, particularly hepatitis $C$ virus $(\mathrm{HCV})^{87}$ and hepatitis B virus (HBV). A DOPPS of HCV status among 76,689 HD patients across three continents, reported that the incidence of HCV infection was 7.5\%, (5.9\% in North America, 6.7\% in Europe and $12.4 \%$ in Japan) ${ }^{88}$. Patients with HCV infection had high hazard ratios of all-cause mortality (1.12) and hospitalization $(4.40)^{88}$. Seroconversion rates ranged from $1.1-3.6 \%$ per 100 patient-years ${ }^{89}$. Another study of 10 countries in the Middle-East reported that HCV prevalence was $25.3 \%$ amongst patients receiving $\mathrm{HD}^{90}$. According to kidney registry data, $\mathrm{HCV}$ rates for 
South African and Ghanaian patients receiving HD in 2017 were similar at $0.8 \%^{91,92}$. A 2021 systematic review and meta-analysis of HD patients in Africa (39 studies, 23,538 participants) reported that the prevalence of HBV and HCV infection was $9.88 \%$ and $23.04 \%$, respectively ${ }^{93}$. HBV prevalence among patients treated with HD from the DOPPS study across North America, Europe and Asia was 3.3\% (ranging from $0 \%$ in the UK to $6.6 \%$ in Italy) and the seroconversion rate was 0.7 per 100 patient-years (ranging from 0.4 in the UK and USA, to 1.2 in Japan) ${ }^{94}$. HBV prevalence among patients treated with HD in South Africa and Ghana was 2.2\% and 3.9\%, respectively ${ }^{91,92}$. A breach in infection control was the main factor responsible for HCV and HBV outbreaks in HD centres ${ }^{87}$. Routine screening for hepatitis infection and adherence to infection control policies are therefore key to preventing these infections. Moreover, HBV vaccination should be considered for all susceptible patients receiving $\mathrm{HD}$ and associated health-care staff to reduce the risk of infection ${ }^{87}$. HD is also associated with a low risk of HIV transmission ${ }^{95}$ and adherence to infection control policies in HD centres is therefore crucial. Registry data indicated that HIV infection rates in South Africa and Ghana in 2017 were $10.6 \%$ and 3.8\%, respectively ${ }^{91,92}$.

Respiratory tract infections are also common (13\%) in patients receiving $\mathrm{HD}^{96}$. In the USA, the incidence of pneumonia among patients treated with $\mathrm{HD}$ $(n=231,202)$ was 21.4 episodes per 100 patient-years; $90 \%$ of affected patients required hospital admission and 30 -day mortality was $10.7 \%{ }^{97}$. A large US observational study reported that all-cause mortality was lower in patients who received an influenza vaccine, either alone (adjusted odds ratio (AOR) 0.8 ) or co-administered with a pneumococcal vaccine (AOR 0.7), compared with those who were not vaccinated ${ }^{98}$. The COVID-19

Box 1 | Strategies to prevent common infections in patients receiving haemodialysis

\section{Prevention of central venous catheter-related bloodstream infection}

- Pre-dialysis education for timely vascular access creation to reduce haemodialysis initiation using a central venous catheter (CVC) line

- Use of special CVC connectors or an antimicrobial barrier cap to reduce CVC-related bloodstream infection (CRBSI) in patients at a high risk or at high-risk facilities

- Selective use of prophylactic antibiotics or antimicrobial locks in patients who require long-term catheter use and are at a high risk of CRBSI

- Staff and patient training and education on CVC and exit-site care

Prevention of arteriovenous fistula or arteriovenous graft infection

- Effective staff education and training on disinfecting the skin at arteriovenous fistula or arteriovenous graft sites before cannulation

- Use of rope ladder cannulation as the preferred technique and limiting arteriovenous access using buttonhole cannulation, which should be avoided in synthetic grafts

Prevention of pneumonia

- All patients receiving haemodialysis should be immunized against influenza, pneumococcus and COVID-19

Prevention of hepatitis virus infection

- Adherence to infection control policy in the dialysis centres

- Hepatitis B vaccine should be considered for susceptible patients and staff from dialysis centres pandemic has been particularly challenging for vulnerable patients receiving HD. A meta-analysis (15 studies, 20,671 participants) reported that the prevalence of COVID-19 among patients on KRT was 3.1\% (95\% CI $1.3 \%-5.7 \%$ ) and the mortality rate was $18.1 \%$ $\left(95 \%\right.$ CI 14.1-23.3) ${ }^{99}$. Of note, these prevalence and mortality rates vary according to community transmission rates at the time. All patients on HD should be immunized against influenza, pneumococcus and COVID-19 to prevent or reduce the severity of respiratory tract infection and associated mortality.

Hospitalization. Patients on HD are at a higher risk of hospitalization than the general population ${ }^{100}$ given the high prevalence of specific risk factors for this outcome among these patients $\mathrm{s}^{101-106}$ (BOX 2). Within the USA, the incidence of overall adjusted hospitalization among patients receiving HD has reduced from 1.88 events per person-year (PPY) in 2009 to 1.63 events PPY in 2018, with corresponding reductions in adjusted lengths of stay from 11.14 to 9.54 days PPY ${ }^{39}$. The causes of hospitalization were reported as cardiovascular (0.43 events PPY), infection ( 0.34 events PPY), vascular (0.14 events PPY) or other (0.69 events PPY $)^{39}$. Similarly, a DOPPS of five European countries observed an overall hospitalization rate of 1.08 episodes PPY, ranging from 0.8 in Spain to 1.58 in France ${ }^{107}$. CVD-related hospitalization ranged from 0.19 to 0.43 episodes PPY, whereas access-related (non-infectious) hospitalization ranged from $0.17-0.41$ PPY using data collected, May 1998 to November $2000^{107}$. A Canadian retrospective study of 38,369 incident dialysis patients ( $80 \%$ of patient received HD) found that all-cause hospitalization was higher in children (2.47 events PPY) than in adults (1.10-1.14 events PPY $)^{108}$. The higher rate of hospitalization in children was primarily related to infection, particularly dialysis-associated infection. Finally, a small retrospective study from Bangladesh reported that the infection-related and cardiovascular-related hospitalization rates were 0.7 and 1.0 events PPY,respectively ${ }^{109}$.

Hospitalization in patients treated with $\mathrm{HD}$ is associated with high health-care costs (approximately one-third of Medicare expenditure for patients receiving dialysis in the USA) and increased mortality ${ }^{39}$. According to US Renal Data System (USRDS) data, approximately $10 \%$ of patients receiving HD died within 30 days of discharge ${ }^{39}$. The SONG-HD initiative recognizes hospitalization as a middle-tier outcome for patients and health-care professionals $^{110}$ (FIG. 2). However, hospitalization data are rarely reported in most national kidney registries.

Few studies have investigated models of care or interventions to reduce hospitalization rates in patients receiving HD. Online haemodiafiltration ${ }^{111,112}$, nocturnal $\mathrm{HD}^{113}$, daily home $\mathrm{HD}^{66}$ and incremental $\mathrm{HD}^{114}$ do not seem to have an effect on hospitalization rates, although the certainty of evidence is low.

Of note, readmission rates are also higher in patients treated with HD than in the general population. A USRDS study ${ }^{39}$ reported a 30-day readmission rate of $34.6 \%$ in 2018 , a rate higher than approximately $17.5 \%$ reported for the general population ${ }^{115}$. Strategies to 
Box 2 | Risk factors for hospitalization in patients receiving haemodialysis

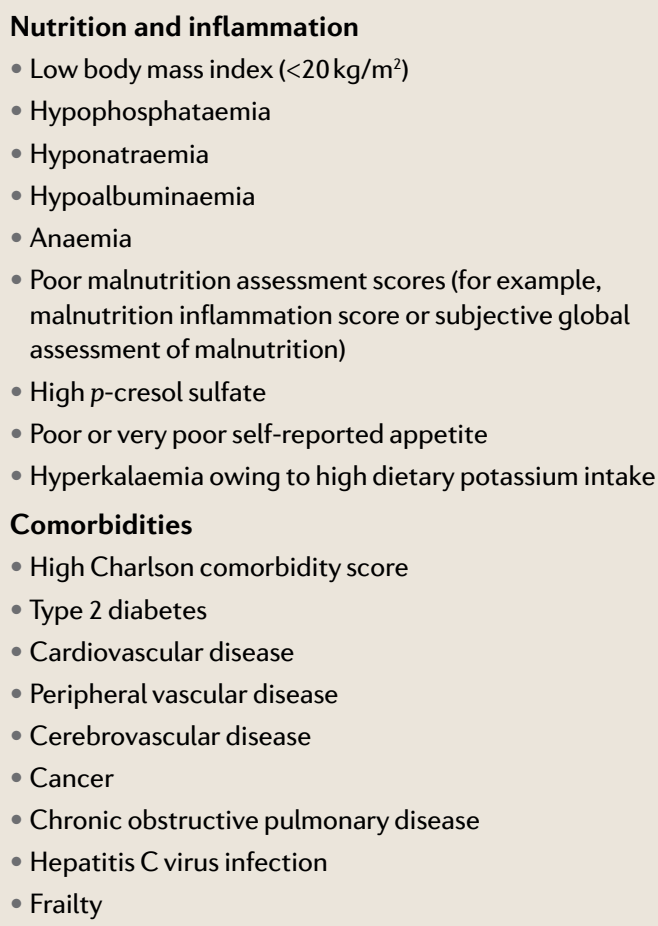

reduce readmission rates have been reported in previous studies $^{116-118}$ (Supplementary Figure 1). Hospitalization and readmission should be treated as a key performance indicator for dialysis providers and should also be reported by national kidney registries using a standardized metric for surveillance and benchmarking.

Cognitive impairment. A 2016 systematic review of 42 studies involving 3,522 patients treated with HD from five continents (North America $n=17$, Europe $n=14$, Middle East or Asia $n=6$, South America $n=3$, Africa $n=2$ ) found that patients receiving HD had worse cognition than the general population, particularly in the domains of orientation, attention and executive function ${ }^{119}$. A subsequent cross-sectional study of 676 adult patients receiving $\mathrm{HD}$ from 20 centres in Italy reported that $71.1 \%$ had impairment of at least one of the five cognitive domains tested ${ }^{120}$. Cognitive impairment is associated with decreased quality of life and increased risk of hospitalization and mortality. General risk factors for cognitive impairment, including ageing, hypertension, diabetes and dyslipidaemia, are often observed in patients treated with HD. Cognitive changes can also be secondary to the effects of HD therapy (for example, hypoxaemia or fluctuations in volume status), as well as the presence of uraemic toxins, metabolic derangements and inflammation associated with kidney failure. Although maintaining an adequate dialysis dose and avoiding intradialytic hypotension are important, more frequent $\mathrm{HD}$ was not associated with neurocognitive benefits in large trials ${ }^{121}$.

\section{Global patient-reported outcomes}

Patient-reported outcomes refer to any outcomes reported directly by patients about how they function or feel in relation to a health condition and its therapy

\section{Demographic factors}

- Limited health literacy

- Smoking

- Minority ethnicity

- Older age

\section{Psychosocial factors \\ - Depression \\ - Anxiety symptoms \\ - Poor social support \\ - Low self-efficacy}

\section{Dialysis access and facility support}

- Use of central venous catheter for vascular access

- Treatment in a centre with a high patient-to-staff ratio

- Non-adherence to dialysis treatment (missed or shortened dialysis sessions)

\section{Others}

- High (>4\%) inter-dialytic weight gain

- Previous history of hospitalization or emergency department visit

- Residence in a nursing facility

without interpretation of the patient's responses by a clinician, or anyone else. These outcomes include any treatment or outcome evaluation obtained directly from patients on HD through interviews, self-completed questionnaires, diaries or other data collection tools such as hand-held devices and web-based forms. Patient-reported outcomes are increasingly becoming an integral part of the delivery and evaluation of care being received by patients on $\mathrm{HD}^{122}$ (TABLE 1).

Fatigue. Fatigue is common and debilitating in individuals undergoing HD. Fatigue is difficult to describe but is defined as a subjective, complex and multidimensional experience that encompasses both physical and psychological domains ${ }^{123}$. Subjective terminologies, such as feeling tired, weak, exhausted or slow, are sometimes used to describe fatigue and some authors have proposed that fatigue should be conceptualized as a continuum, with exhaustion and tiredness at one end, and energy and vitality at the opposite extreme ${ }^{124}$. Several studies showed that fatigue in patients receiving HD is associated with poor outcomes, including reduced sleep quality ${ }^{125}$, poor quality of life (QOL) ${ }^{126}$, increased CVD ${ }^{127}$, increased hospitalization $^{127}$ and increased all-cause mortality ${ }^{125,127}$. Fatigue is most severe on dialysis days compared with non-dialysis days ${ }^{128}$.

The prevalence of fatigue varies widely in patients receiving long-term dialysis ${ }^{129}(60-90 \%)$. This variation is partly due to considerable heterogeneity in the types of instruments used to measure fatigue ${ }^{130-133}$. Of these, the Functional Assessment of Chronic Illness Therapy - Fatigue (FACIT-F) questionnaire, which includes 13 fatigue-related questions, is the only multi-item survey designed to ascertain multiple dimensions of fatigue ${ }^{131}$. However, the vitality scale of the SF-36 questionnaire ${ }^{133}$, 
which contains four fatigue-related items, is the most widely used fatigue instrument in the dialysis population. The SONG-HD group recommended that a core outcome measure of fatigue should assess the impact of fatigue on three measures: life participation, tiredness and level of energy, all of which ranked as highly important among patients, caregivers and health-care professionals $^{134}$. These measures have been validated in a SONG-HD fatigue study that comprised 485 patients from different countries who were receiving $\mathrm{HD}^{28}$.
Although multiple factors have been associated with fatigue in patients with kidney failure, the aetiology of fatigue remains largely unknown and can be divided into four categories: dialysis-related, physiological, associated with psychological or behavioural factors, or associated with socio-demographic factors (Supplementary Figure 2). Inflammation is a central mediator of fatigue in patients with kidney failure ${ }^{129,135}$ and inflammatory markers, such as IL-6 and C-reactive protein (CRP), are elevated in patients receiving $\mathrm{HD}^{136}$. Inflammation

Table 1 | Patient-reported outcomes in patients receiving haemodialysis

\begin{tabular}{|c|c|c|c|c|}
\hline Measure & Definition & Prevalence or incidence & Clinical impact & Refs \\
\hline Fatigue & $\begin{array}{l}\text { Subjective, complex and } \\
\text { multidimensional experience (for } \\
\text { example, weakness and/or lethargy) } \\
\text { that encompasses both physical and } \\
\text { psychological domains }\end{array}$ & Widely variable prevalence; $60-97 \%$ & $\begin{array}{l}\text { Reduced sleep quality; poor } \\
\text { QOL; increased risk of CVD, } \\
\text { hospitalization and all-cause } \\
\text { mortality }\end{array}$ & $123-134$ \\
\hline Life participation & $\begin{array}{l}\text { Ability to engage in everyday life } \\
\text { events (for example, work, travel, } \\
\text { recreation, study and/or physical } \\
\text { activity) }\end{array}$ & $\begin{array}{l}\text { Prevalence is highly variable and difficult } \\
\text { to measure; influenced by multiple factors: } \\
\text { method of HD delivery (in-centre HD } \\
\text { versus home HD), treatment schedule, } \\
\text { need for repeated invasive procedures, } \\
\text { HD symptoms (for example, post-dialysis } \\
\text { fatigue) and complications (for example, } \\
\text { pruritus, dizziness or headaches) }\end{array}$ & $\begin{array}{l}\text { Affects patients' choices of } \\
\text { treatment and modalities, as well } \\
\text { as outcomes; can impact QOL }\end{array}$ & $22,24,142,143$ \\
\hline Depression & $\begin{array}{l}\text { A mood disorder that causes a } \\
\text { persistent feeling of sadness and loss } \\
\text { of interest in everyday life activities, } \\
\text { and leads to a variety of emotional } \\
\text { and physical consequences }\end{array}$ & $\begin{array}{l}\text { Variable; global representative data } \\
\text { suggest a prevalence of } 22.8 \%(95 \% \mathrm{Cl} \\
18.6-27.6 \%) \text { based on interview and } 39.3 \% \\
\text { ( } 95 \% \mathrm{Cl} 36.8-42.0 \%) \text { based on self-report } \\
\text { scales }\end{array}$ & $\begin{array}{l}\text { Increased risk of mortality, } \\
\text { hospitalizations, non-adherence } \\
\text { to dialysis and lower HR-QOL }\end{array}$ & $145-156$ \\
\hline Cramps & $\begin{array}{l}\text { Intradialytic painful involuntary } \\
\text { musculature contraction }\end{array}$ & Incidence $24-86 \%$ & $\begin{array}{l}\text { Reduced quality of dialysis } \\
\text { (reduced time on treatment and } \\
\text { interruptions); reduced QOL }\end{array}$ & $165-168$ \\
\hline Pain & $\begin{array}{l}\text { Localized or generalized unpleasant } \\
\text { bodily sensation leading to mild } \\
\text { to severe physical discomfort and } \\
\text { emotional distress }\end{array}$ & $\begin{array}{l}\text { A systematic review and meta-analysis } \\
\text { of } 48 \text { studies involving } 8,464 \text { patients } \\
\text { from } 23 \text { countries reported a } 60.5 \% \text { mean } \\
\text { prevalence of chronic pain }\end{array}$ & $\begin{array}{l}\text { Insomnia and depression; } \\
\text { reduced QOL }\end{array}$ & 171,173 \\
\hline \multirow[t]{2}{*}{$\begin{array}{l}\text { Sexual } \\
\text { dysfunction }\end{array}$} & \multirow[t]{2}{*}{$\begin{array}{l}\text { Persistent, recurrent problems with } \\
\text { sexual response, desire, orgasm or } \\
\text { pain that affect sexual relationships }\end{array}$} & $\begin{array}{l}\text { A systematic review found that the } \\
\text { prevalence of erectile dysfunction in male } \\
\text { patients was } 75 \% \text { (95\% Cl 72-77\%) }\end{array}$ & \multirow[t]{2}{*}{$\begin{array}{l}\text { Decreased QOL; increased risk } \\
\text { of CVD morbidity and mortality. }\end{array}$} & \multirow[t]{2}{*}{187} \\
\hline & & $\begin{array}{l}\text { Only one study reported on sexual } \\
\text { dysfunction in } 138 \text { female patients, and } \\
\text { observed a prevalence of } 29.7 \%\end{array}$ & & \\
\hline Sleep quality & $\begin{array}{l}\text { A measure of whether sleep is restful } \\
\text { and restorative }\end{array}$ & $\begin{array}{l}\text { An assessment of sleep quality in } \\
11,351 \text { patients from } 308 \mathrm{HD} \text { units in } \\
7 \text { countries reported a } 49 \% \text { prevalence } \\
\text { of poor sleep quality }\end{array}$ & $\begin{array}{l}\text { Increased mortality; increased } \\
\text { risk of CVD; decreased QOL }\end{array}$ & 189 \\
\hline
\end{tabular}


mediates fatigue either directly through activation of the central nervous system, hypothalamus, pituitary gland and adrenal glands, or indirectly by inducing sleep disorders, depression or anxiety ${ }^{137}$. No specific treatment strategies are available for the management of fatigue in dialysis. Data for the use of pharmacological interventions (for example, growth hormone, steroids, vitamins, alkali supplementation and erythropoiesis-stimulating agents) remain conflicting and inconclusive ${ }^{138}$. Of the non-pharmacological interventions, regular physical activity has a positive effect on fatigue ${ }^{139}$. Intradialytic cardiovascular exercise training reduced inflammation and improved physical performance in patients receiving $\mathrm{HD}^{140}$. A systematic review comprising 20 trials (677 participants) $)^{141}$ reported that aerobic and combined exercise was useful for improving QOL in patients treated with HD. However, larger trials are needed to assess the effect of exercise and other treatment strategies on fatigue in the HD population.

Life participation. Life participation is the ability to engage in everyday life events (for example, work, travel, recreation, study and physical activity) and is a crucially important outcome for patients on $\mathrm{HD}^{22,24}$. Reduced life participation among these patients can be influenced by HD delivery method (in-centre HD versus home HD), treatment schedule, the need for repeated invasive procedures (for example, catheter (re)placement or fistula repair surgeries), symptoms of HD (for example, post-dialysis fatigue) and occurrence of complications (for example, pruritus, dizziness, or headaches). Restrictions to life participation affect patients' choices of treatment modalities and outcomes ${ }^{142}$.

The SONG-HD group assessed patients receiving $\mathrm{HD}$ and their caregivers and identified that the ability to travel and to work, dialysis-free time, the impact of dialysis on family and/or friends, and mobility were important middle-level priority outcomes ${ }^{24}$ (FIG. 1). Although the ability to travel ranked higher than the ability to work in the SONG-HD study ${ }^{24}$, staying employed has been associated with increased QOL across multiple dimensions ${ }^{143}$, increased probability of receiving a kidney transplant and better survival on $\mathrm{HD}^{144}$.

Depression. Approximately one in five patients receiving dialysis suffers from depression, a rate that far exceeds that of the general population and of most patients with chronic illnesses ${ }^{145,146}$. A systematic review and meta-analysis of 198 population studies (46,505 patients receiving dialysis) across four continents (including the USA, Canada, Brazil, UK, Norway, France, The Netherlands, Turkey, Saudi Arabia, Egypt, Sri Lanka, Korea and Taiwan), demonstrated that the prevalence of depression was $22.8 \%$ (95\% CI 18.6-27.6\%) based on interview and $39.3 \%$ (95\% CI 36.8-42.0\%) based on self-report scales ${ }^{146}$. In the DOPPS II population, the prevalence of physician-diagnosed depression was lowest in Japan (2\%) and France (10.6\%), and highest in the USA $(21.7 \%)$ and Sweden $(19.8 \%)^{147}$.

The relationship between CKD and depression is complex and multi-factorial ${ }^{148}$ (Supplementary Figure 3 ). Socio-economic disadvantage leading to unhealthy lifestyles is an important risk factor for depression ${ }^{149}$, as are biopsychosocial consequences, such as inflammation, negative self-care behaviours, symptom burden (particularly fatigue and sleep disturbance) and a sense of loss in many life domains ${ }^{150-153}$.

The evidence linking depression with adverse events such as mortality, hospitalizations and a decrease in health-related QOL (HR-QOL) among patients with CKD is growing. A systematic review of 22 studies comprising 83,381 patients found a consistently increased risk of death from any cause among patients with depression (relative risk (RR) 1.59; 95\% CI, 1.35-1.87) across all stages of CKD, regardless of sex, age or the method of diagnosing depression ${ }^{154}$. In the DOPPS population, depression was independently associated with death and hospitalization among patients receiving $\mathrm{HD}^{155}$. Depression is also associated with difficulties adhering to the recommended diet for patients living with kidney failure on dialysis and also fluid restriction and dialysis non-adherence ${ }^{150,151}$, and is a major catalyst for the deterioration in HR-QOL commonly experienced by patients with $\mathrm{CKD}^{152,156}$.

Although depression is common and impactful in the dialysis population, it remains significantly under-recognized and mostly under-treated (only a minority of patients receive anti-depressant medication $)^{147}$. This trend might relate, in part, to conflicting ideas regarding the value of screening for depression with self-administered questionnaires, such as the Beck Depression Inventory ${ }^{157}$, and the limited evidence base supporting the use of both pharmacological and psychosocial interventions. Self-administered questionnaires are thought to have limited diagnostic accuracy and a tendency to incorrectly label the increased somatic symptoms commonly experienced by patients receiving dialysis such as symptoms of depression ${ }^{158}$. The evidence supporting treatment with antidepressant medication is scant - two RCTs show either unsustained or no benefit of serotonin reuptake inhibitors on depression scores ${ }^{159,160}$, and the safety profile of these medications in patients receiving dialysis is uncertain. To date, no conclusive evidence shows that alteration of the dialysis regimen is beneficial ${ }^{47}$ but a 2019 Cochrane review found that cognitive behavioural therapy, exercise and relaxation techniques might have a role in reducing depressive symptoms ${ }^{161}$.

Anxiety. A 2021 systematic review of 61 observational studies from Europe, North America, Asia and Africa reported a high prevalence $(42 \%)$ of elevated anxiety symptoms among patients receiving dialysis ${ }^{162}$. Furthermore, elevated anxiety symptoms were associated with depression, decreased parathyroid hormone levels, increased length of hospitalization, and decreased perceived quality of life and vitality levels ${ }^{162}$. The postulated underlying mechanisms for anxiety in HD include the presence of uraemic toxins, oxidative stress, cerebrovascular damage, renin-angiotensinaldosterone system activation, stressors associated with kidney failure (for example, high pill burden, and dietary and/or fluid restrictions) and dialysis therapy (for example, time and financial burden $)^{162,163}$. Although few studies have evaluated anxiety treatment strategies, 
one investigation in patients receiving HD reported that a brief cognitive-behavioural therapy intervention decreased anxiety and depressive symptoms, and improved QOL after a 4-week follow-up ${ }^{164}$.

Cramps. The incidence of muscle cramps in patients with HD ranges from 24 to $86 \%{ }^{165,166}$. The underlying mechanism is not fully understood, but a high ultrafiltration rate and high volume contraction have been implicated ${ }^{167}$. The frequency of cramps seems to be directly related to the percentage reduction in body weight achieved during treatment and with the initiation of $\mathrm{HD}^{168}$. Unfortunately, no reliable, evidence-based therapy to reduce muscle cramps associated with HD is currently available ${ }^{169}$. Therapies that are commonly prescribed include quinine, vitamin E, prazosin, carnitine, stretching, exercise and more frequent dialysis ${ }^{165}$. A 2006 study reported that the traditional Japanese herbal medicine shakuyaku-kanzo-to was effective in preventing $\mathrm{HD}$-associated muscle cramps ${ }^{170}$. Patients receiving HD have recognized cramps as one of the top three physical symptoms that should be designated as priority targets for novel therapies ${ }^{23}$.

Pain. A systematic review of 52 studies involving 6,917 HD patients from 10 countries ${ }^{171}$ reported that the prevalence of chronic pain ranged from 33 to $82 \%$, whereas the prevalence of acute pain (defined as current pain, intradialytic pain or pain during the past 4 weeks) ranged from 21 to $92 \%$. A subsequent systematic review and meta-analysis of 48 studies involving 8,464 patients on dialysis from 23 countries ${ }^{172}$, showed that the mean prevalence of chronic pain was $60.5 \%$. However, the researchers noted that studies lacked a uniform approach to defining the chronicity and nature of pain, and that the tools used to determine pain severity were variable. Pain in patients receiving $\mathrm{HD}$ is associated with insomnia and depression ${ }^{173}$.

The causes of pain in patients treated with HD are not fully understood and experts suggest that it is often multifactorial ${ }^{174}$. Pain among the HD population can be related to underlying chronic conditions (for example, diabetic neuropathy) and/or causes unique to kidney failure (for example, calciphylaxis and renal osteodystrophy $)^{174}$. Moreover, interventions related to HD treatment such as the placement of central catheters and AVFs can lead to painful syndromes ${ }^{174}$. Treatment of the underlying cause, if identifiable, is key in pain management. Non-pharmacological approaches might be appropriate for musculoskeletal pain. For pharmacological management, a modified WHO analgesic ladder can be used. Pharmacological management of pain for HD patients requires careful selection of analgesics with close attention to efficacy and safety, particularly for opioids $s^{175,176}$. Focus on function and QOL rather than complete pain alleviation is recommended when caring for patients on HD with pain.

Abnormal nerve sensations similar to paraesthesias but representing features of a more chronic nature that can affect both upper and lower limbs with the predominant features of prickling, burning, stabbing, ice-cold or electrical sensations. different tools and questionnaires reported a mean prevalence of 55\% (Supplementary Table 1). In a large prospective study using DOPPS data from seven countries, moderate to extreme pruritus was reported by $42 \%$ of 18,801 patients receiving $\mathrm{HD}^{178}$. Of note, pruritus was associated with a $17 \%$ higher mortality risk, although this relationship was not significant after adjusting for sleep quality measures. The underlying mechanism for development of pruritus in patients on HD is uncertain, and two concepts - 'immuno-hypothesis' and the 'opioid hypothesis' - are postulated as possible mechanisms for the pathogenesis of uraemic pruritus ${ }^{179}$. Proposed treatments for pruritus include the use of moisturizing agents, control of CKD-mineral bone disease (MBD) parameters, the use of $\alpha_{2} \delta$ channel ligands (for example, gabapentin and pregabalin), antihistamines, cromolyn sodium, phototherapy, $\kappa$-opioid receptor agonists (for example, difelikefalin) ${ }^{180}$ and $\mu$-receptor antagonists.

Restless legs syndrome. Restless legs syndrome (RLS) is characterized by a desire to move the extremities that is often associated with paraesthesias and/or dysaesthesias; motor restlessness; worsening of symptoms at rest with at least temporary relief by activity, and worsening of symptoms in the evening or at night ${ }^{181}$. The reported prevalence of RLS in HD populations is variable ${ }^{182}$, ranging from 12 to $62 \%$. The use of different assessment tools might explain this variation. Studies using the International Restless Legs Syndrome Study Group diagnostic criteria have reported the prevalence of RLS to range between 10 and $20 \%{ }^{182}$. Another study used a validated and relatively simple self-report survey, the RLS Questionnaire, and found that $14 \%$ of 113 patients on dialysis were affected by RLS ${ }^{182}$. This condition is associated with sleep disturbances, decreased quality of life, premature withdrawal from dialysis ${ }^{183}$, and increased cardiovascular morbidity and mortality ${ }^{184}$. The pathogenesis is not well understood but seems to involve abnormal neurological intracellular ion fluxes, and the dopaminergic and other neurotransmitter pathways ${ }^{185}$. Therapeutic strategies for improvement include physical exercise, reduced caffeine intake, augmented dialysis, sleep hygiene, treatment of iron deficiency and the use of $\alpha_{2} \delta$ channel ligands, dopamine agonists or opioids ${ }^{186}$.

Sexual function. A systematic review of 50 observational studies of 8,343 patients with CKD, including 27 studies (54\%) involving 4,146 patients receiving HD found that the prevalence of erectile dysfunction in male patients receiving dialysis was $75 \%$ (95\% CI 72-77\%) $)^{187}$. Only one study reported on sexual dysfunction in 138 female patients treated with HD and observed a prevalence of 29.7\% using a standard Female Sexual Function Index (FSFI) questionnaire ${ }^{187}$. Sexual dysfunction in males and females was associated with older age, diabetes mellitus and depression ${ }^{187}$. A Cochrane systematic review of 15 RCTs (11 involving HD patients and one involving female patients) found that phosphodiesterase- 5 inhibitors improved various aspects of erectile function patients on $\mathrm{HD}^{188}$. In addition, oral zinc supplementation was associated with an increase in plasma testosterone 
concentration, along with an increase in the potency and frequency of intercourse. However, the addition of zinc to the dialysate did not improve testosterone levels. The safety and efficacy of interventions for sexual dysfunction in women receiving HD were uncertain.

Sleep quality. In 12 studies of patients receiving $\mathrm{HD}$ from 10 countries in North America, Canada and Asia, the mean prevalence of poor sleep quality was $69 \%$ in 10 studies based on a Pittsburgh Sleep Quality Index $>5$ and $83 \%$ in 2 studies based on a Pittsburgh Sleep Quality Index $\geq 5$ (Supplementary Table 2). A DOPPS assessment of sleep quality in 11,351 patients receiving HD in 308 HD units in seven countries reported a $49 \%$ prevalence of poor sleep quality, defined as a score of $\leq 5$ on the KDQOL-SF-36 $\left(\right.$ REF $\left.^{189}\right)$. Notably, the study reported an independent association between poor sleep quality and increased mortality. Identification and treatment of sleep disorders and other aforementioned factors underpinning poor sleep quality (for example, depression, anxiety, cramps, pain, restless leg syndrome and pruritus) are important.

Surrogate outcomes. These outcomes comprise intermediate endpoints of a clinical outcome and are considered to be valid predictors (surrogates) of the final clinical outcome. Blood pressure and CKD-MBD are established surrogates for CVD and/or mortality in HD.

Blood pressure. Hypertension is common among patients receiving HD. Data from the GKHA showed that blood pressure, which is a quality indicator for $\mathrm{HD}$, was measured and reported in most countries $(86 \%)^{14}$. In the vast majority (93\%) of countries, blood pressure was monitored through analogue techniques (or less commonly (79\%) through automated monitoring $)^{14}$. The optimal blood pressure target in the HD population remains controversial ${ }^{190}$. Similar to previous studies $^{191,192}$, a prospective cohort study of 2,299 patients undergoing chronic dialysis ${ }^{193}$ revealed a U-shaped relationship between pre-dialysis systolic blood pressure and all-cause mortality, with a nadir at systolic blood pressure 110-169 $\mathrm{mmHg}$.

CKD-MBD. CKD-MBD is the term used to describe disturbances in mineral metabolism, kidney bone disease and vascular calcification, and is associated with heightened CVD and mortality ${ }^{194}$. In a survey of 13 countries, the prevalence of secondary hyperparathyroidism (SHPT; that is, serum parathyroid hormone levels $>300 \mathrm{pg} / \mathrm{ml}$ ) varied widely between 30 and 50\%, among dialysis-dependent populations ${ }^{195}$. Similarly variable results were reported across Europe (30-46\%, $n=7$ ), North America (54\%), Australia and New Zealand (49\%), India (28\%), Japan (11.5\%) and Brazil (10\%) $)^{195}$. A cross-sectional study of 48 patients at a Nigerian HD unit ${ }^{196}$ reported that CKD-MBD was common (58\%).

The mainstay of treatment for mineral metabolism disturbances in patients receiving HD involves dietary phosphate restriction, the use of phosphate binders, vitamin D supplementation, the use of calcimimetic agents and parathyroidectomy ${ }^{194}$. However, medications to optimize CKD-MBD are responsible for a large proportion of the daily pill burden for these patients ${ }^{197}$, contribute substantially to excess health-care costs and, given the low certainty of evidence, might not improve outcomes that are important to patients such as mortality ${ }^{198,199}$. A Pragmatic randomized trial of High Or Standard PHosphAte Targets in 3,600 adult patients with End-stage kidney disease on dialysis (PHOSPHATE trial) is currently underway in Australia, New Zealand, UK and Canada (NCT03573089).

\section{Other HD outcomes}

In addition to the aforementioned outcomes, socioeconomic (non-clinical) factors that affect the day-to-day lives of people on HD should also be considered. Practitioners should recognize these factors and how they affect the lives of patients (for example, their effects on relationships or personal finances), their families and their caregivers as an important step towards developing interventions to ameliorate their negative impact.

Impact on family and friends. Similar to other chronic illnesses, the burden of HD care often extends beyond patients to their families, caregivers and friends ${ }^{200,201}$. In a study involving 84 older individuals receiving in-centre $\mathrm{HD}$ in Brazil, most caregivers were women, married and a spouse or child of the patient, and devoted a median of $70 \mathrm{~h}$ per week (range: $14-148 \mathrm{~h}$ ) to care activities ${ }^{202}$. The study noted that HD caregivers had lower QOL in all Medical Outcomes Study 36-Item Short Form Survey (SF-36) domains compared with the general Brazilian population ${ }^{202}$. Several other studies from around the globe, including the USA (patients on HD or PD, and kidney transplant recipients) ${ }^{203}$, Italy (patients on HD) ${ }^{204}$, China (patients on PD) ${ }^{205}$, India (paediatric patients) ${ }^{206}$ and Jordan (patients on HD) ${ }^{207}$ have shown a similar impact on caregivers.

Increased social support has been associated with less hospitalization and better QOL in patients receiving dialysis $^{208}$. Recognizing the impact of kidney failure and maintenance dialysis therapy on family and caregivers is an important step towards developing interventions aimed at decreasing caregiver burden and increasing patient support ${ }^{205}$. Developing educational and training programmes tailored for families and caregivers might decrease the burden of knowledge and unexpected care needs ${ }^{203}$. Providing psychological support and coping skills to a caregiver might also improve the well-being of patients and their care providers ${ }^{203}$. Although home dialysis therapy might increase the care needs of patients at home ${ }^{209}$, a significant difference in the responsibility level for caregivers of patients treated with home HD compared with PD has not been reported ${ }^{209}$. In an ongoing international trial, preliminary results showed a more significant decrease in QOL in caregivers of patients randomized to extended-hours HD than those receiving standard-hours $\mathrm{HD}^{210}$.

Financial impact. Providing life-saving maintenance HD comes at a high societal and personal cost, especially in LMICs ${ }^{211}$. Among the different KRT modalities, in-centre HD incurs the highest cost per patient ${ }^{212}$. 
According to data available from 97 countries, the average annual cost of maintenance HD (specifically, in-centre HD) was 22,617 international dollars (equivalent to the value of US dollars in 2016) per person per year, but this cost varied widely within countries and by World Bank income group (Supplementary Figure 4) ) $^{213}$. The probability of paying out-of-pocket for HD was inversely related to country income level. Patients paid $100 \%$ of HD treatment costs in $14 \%$ of LICs, compared with $11 \%$ of LMICs, $7 \%$ of UMICs and $4 \%$ of $\mathrm{HICs}^{213}$. By contrast, patients paid no out-of-pocket costs for HD in $39 \%$ of HICs, compared with $20 \%$ of UMICs, $17 \%$ of LMICs and 23\% of LICs. In LMICs, where most of the cost burden is shifted from public to private funds, lack of HD can often lead to early death ${ }^{213}$ More innovations in the provision of HD care that are cost-effective are needed. A policy shift from in-centre to home-based dialysis will probably lead to less societal cost burden in resource-rich countries ${ }^{212}$.

\section{HD outcomes in vulnerable populations}

Vulnerable population subgroups, including people at the extremes of age (children and older individuals), women and Indigenous peoples across the various world settings are further disadvantaged by socio-economic variables such as their racial or ethnic group, income level, insurance coverage (or lack thereof), housing conditions, literacy and access to care or health system organization.

Women. Men outnumber women by a ratio of 2 or 3 to 1 in the dialysis population ${ }^{39}$ (FIG. 3). Analysis of over 230,000 patients receiving KRT in Europe from 1965 to 2005 showed a consistently higher male-to-female ratio for incident and prevalent $\mathrm{KRT}^{214}$. The ratio increased over time and was consistent across countries. At HD commencement, women were generally older, had lower kidney function, fewer comorbidities, greater catheter use and fewer fistula attempts, and were less likely to receive $\geq 12 \mathrm{~h}$ of dialysis per week than men ${ }^{215-217}$. Other studies have also reported that, compared with men, women on HD have a higher symptom burden, greater symptom severity, poorer HR-QOL, longer recovery time after a dialysis session, an $18 \%$ higher risk of withdrawal from dialysis and a $20 \%$ higher hospitalization rate ${ }^{218-224}$.

The survival advantage of women compared with men at higher levels of GFR diminishes as kidney function declines. A DOPPS report of 206,374 patients on HD showed that the male-to-female mortality ratio was 1 , which is lower than the that of the general population $(1.5-2)^{225}$. These data show that, relative to age- and sex-matched individuals from the general population, women have a 1.5 times higher standardized mortality than men. This risk is further exacerbated in younger

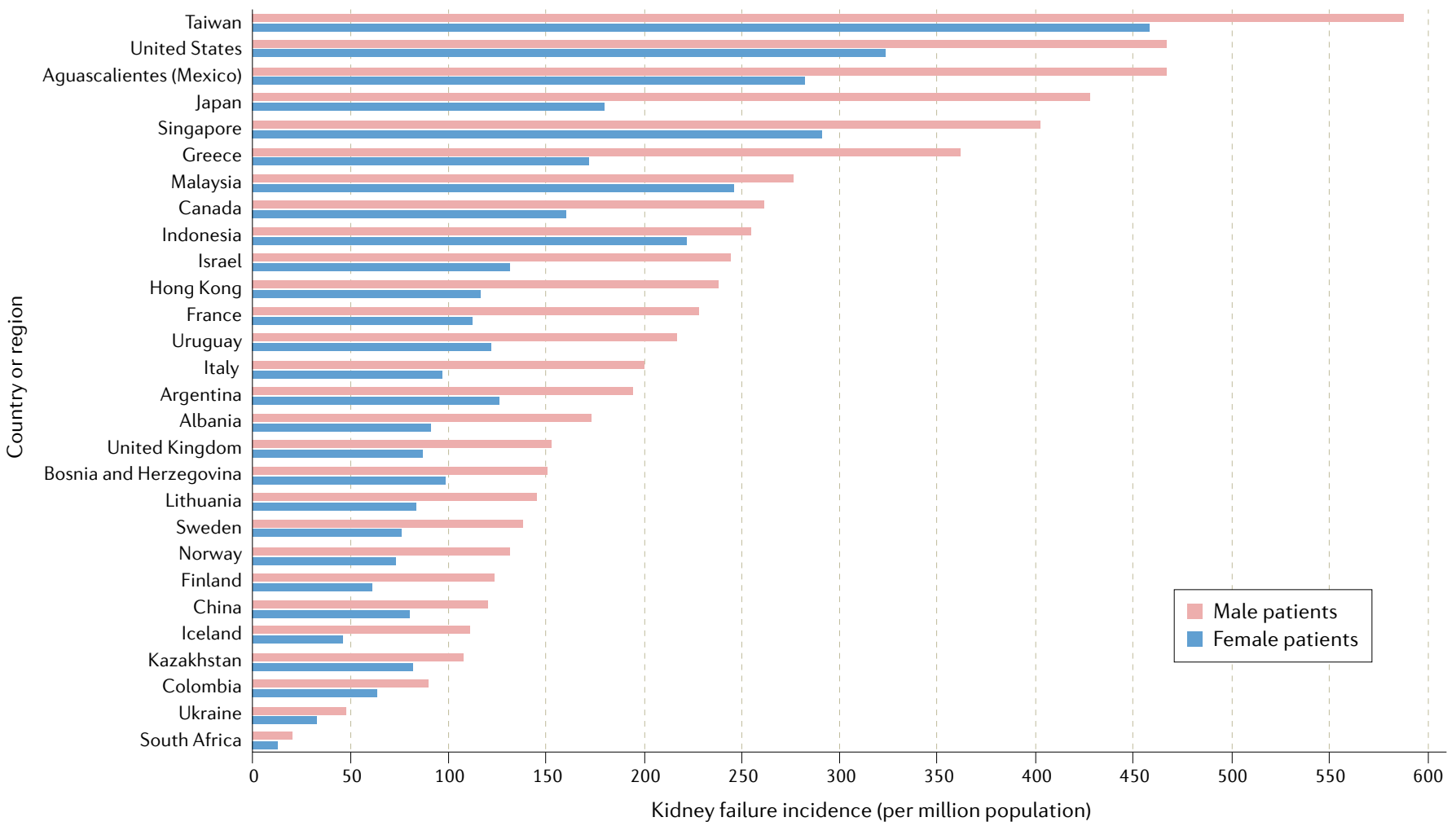

Fig. 3 | Incidence of treated kidney failure by sex in different countries or regions (2018). The figure depicts an international comparison of the incidence of treated kidney failure by country or region displaying information among countries and regions that supplied data to the US Renal Data System for the year 2018. The highest incidences $(\geq 400$ persons with treated kidney failure per million population) were observed in the Mexican state of Jalisco, Taiwan and Hungary, whereas the lowest incidences $(<100$ persons with treated kidney failure per million population) were reported in Kazakhstan, Finland, Iceland, Colombia, Chile, Bangladesh, Ukraine and South Africa. Data for Canada exclude Quebec. Data for Italy are representative of $38 \%$ of patients with kidney failure. Japan data include only patients receiving dialysis. UK data include only England, Wales and Northern Ireland (data for Scotland are reported separately). Data collection methods vary across countries, prompting caution in making direct comparisons. Graph is reprinted from United States Renal Data System ${ }^{39}$, CC BY 4.0 (https://creativecommons.org/licenses/by/4.0/). 
$K t / V$

A formula for measuring

and expressing the degree of

dialysis small solute clearance

using biochemical parameters

( $K$, dialyzer clearance (that is,

the rate at which blood passes through the dialyzer) expressed in $\mathrm{ml} / \mathrm{min}$; $t$, time; $V$, volume of total body water). women ${ }^{226}$. USRDS data, showed a $36 \%$ greater mortality risk in girls aged 2 to 19 years receiving HD than boys of the same age ${ }^{227}$. This difference has been attributed to a higher prevalence of inflammatory diseases amongst younger women or incorrect calculation of dialysis dose based on $K t / V$, as suggested by a secondary analysis of the HEMO data ${ }^{228,229}$.

Older individuals. The demand for dialysis is growing in elderly populations worldwide, with the highest growth in those $>80$ years of age $e^{230}$. Analysis of 8,161 patients on HD from DOPPS countries showed a higher burden of comorbidities and malnutrition, lower fistula use (in North America and Europe), poorer QOL (physical scores) and higher mortality amongst those over the age of 75 years, than in their younger counterparts ${ }^{231}$. Median survival on dialysis was 1.6-5.4 years shorter than in those under the age of 45 . USRDS data show 4 -fold higher mortality in patients over the age of 75 years on HD than in the general population ${ }^{39}$. A systematic review of 28 studies $^{232}$ identified an independent association between increased mortality in older individuals receiving $\mathrm{HD}$ and functional impairment (OR 1.45, 95\% CI 1.20-1.75), cognitive impairment (OR 1.46, 95\% CI 1.32-1.62), falls (OR 1.14, 95\% CI $1.06-1.23$ ), frailty (OR $1.43,95 \%$ CI $1.31-1.56$ ) and central venous catheter use (OR 1.53, 95\% CI 1.44-1.62).

Older individuals treated with $\mathrm{HD}$ are also more frequently affected by pain, sleep disturbances and depression than younger patients ${ }^{233}$. Based on a qualitative study ${ }^{234}$, researchers identified predictors of better outcomes in older individuals on dialysis. These predictors included physical factors (less frailty, greater ability to tolerate dialysis and the presence of functional vascular access), psychological factors (reasonable expectations from dialysis, understanding of the need for lifestyle changes and positive attitudes), social factors (involvement of family and friends, and ability to engage in other activities) and provider factors (easy access to dialysis and availability of advance care planning). Rather than survival, improving quality of life, or meeting functional or emotional goals, might be more important for older individuals with kidney failure ${ }^{235}$. Consequently, they are more likely to withdraw from HD than younger patients.

Children. Children and adolescents with kidney failure have unique characteristics and needs. Similar to adults, kidney transplantation is the optimal KRT modality for children and adolescents. Access to dialysis is highly restricted in paediatric populations in LICs and LMICs owing to lack of specialized equipment and ability to pay for treatment ${ }^{236,237}$. According to a systematic review, about $80 \%$ of all children receiving KRT lived in Europe, North America or Japan ${ }^{238}$.

The mortality of children on dialysis is 30 -fold higher than in the general paediatric population ${ }^{239}$. According to the USRDS, children starting dialysis before the age of 14 had a remaining lifetime of 22-24 years ${ }^{215}$. European children starting dialysis between 2005 and 2010 had a 5 -year survival of $89.5 \%{ }^{240}$, whereas the mortality rates were $4.8 / 100$ patient-years amongst children on HD in Australia and New Zealand ${ }^{241}$. Mortality is particularly high in children under the age of 5 (49.4 and 83.4 deaths/1,000 patient-years in Europe and USA respectively ${ }^{239,240}$. The survival of children on HD has improved over time, with risk reductions of $12-20 \%$ for every five calendar years between 1990 and $2010\left(\mathrm{REF}^{2}{ }^{240}\right)$. In a multi-continent study ${ }^{242}$ comprising 3,244 patients aged $0-30$ years, the mortality in the population aged 18-30 years was higher in North and South America than in Europe (North America OR 2.69, CI 1.29-5.63; South America OR 4.21, CI 2.32-7.6). North American children also had a higher co-morbidity burden than all other regions, and greater use of catheters than the South America region. Globally, patients from Asia had the longest mean treatment times, whereas the North American cohorts had the shortest.

Physical growth, QOL and adaptation to the demands of adulthood are important considerations in the paediatric HD population. Growth is influenced by the quality of dialysis and availability of growth hormone therapy, both of which vary worldwide ${ }^{238}$. According to the International Paediatric Dialysis Network, treatment rates are highest in Europe, where $30-50 \%$ of children $<18$ years on HD received growth hormone ${ }^{238}$. Delayed autonomy, and psychosexual and social development are other important issues ${ }^{243}$. Data from European countries have shown that, with appropriate support, educational attainment and future employment among children on HD can be similar to that of their age-matched counterparts in the general population ${ }^{238}$.

Indigenous populations. The incidence and prevalence of kidney failure are greatly increased in Indigenous populations compared with non-Indigenous individuals in countries such as the USA, Australia, New Zealand and Canada $^{244,245}$. In Australia, Aboriginal and Torres Strait Islander peoples use KRT five times more frequently than other Australians ${ }^{246}$. Indigenous patients are also younger and have a higher comorbidity burden than their non-Indigenous counterparts ${ }^{244}$. A combination of population-specific and socio-economic factors, remote location and poor access to health care are responsible for the higher burden of kidney disease in Indigenous populations. About $50 \%$ of Aboriginal and Torres Strait Islander patients with kidney failure live in areas without dialysis facilities and over $75 \%$ need to relocate to have access to treatment ${ }^{247,248}$.

The outcomes amongst Indigenous people on HD vary between countries. In a retrospective cohort study that compared 263 Indigenous and 10,713 non-Indigenous individuals over 65 years of age in the Australian and New Zealand data Registry, Indigenous people had a $20 \%$ increased risk of mortality $(95 \% \text { CI } 2-41 \%)^{249,250}$. By contrast, American Indians and Native Alaskans (AI/NA) with diabetes have similar or better survival on HD than their white counterparts ${ }^{251}$. The patients who reported AI/NA ancestry had better survival, and those with AI ancestry as reported on the USRDS database had the lowest adjusted risk of death compared with white individuals (HR 0.58, 95\% CI 0.55-0.61) ${ }^{252}$. The reason for this survival advantage is unclear. Although the study adjusted for a number of baseline differences, the role of unmeasured confounders cannot be excluded. 
Hub and spoke model A distribution method in which a centralized 'hub' (for example, a large HD unit in a tertiary centre, with a complete set of resources and personnel) supports other smaller units (most commonly at remote sites, virtually and/or via outreach visits by nephrologists and other health professionals, including dietitians and nurse educators)
Several interventions to improve outcomes in remote dwelling Indigenous populations have been investigated, including involving people from the same communities in patient care, the use of a hub and spoke model of HD delivery and telehealth ${ }^{253,254}$. These interventions were more likely to be successful when the target communities were included in program development ${ }^{255}$. Several studies have documented improved outcomes (QOL and survival) when Indigenous people receive HD in units close to home ${ }^{256-258}$. In an analysis of 77 patients dialyzed at the Kimberley Satellite Program (Australia), which implemented targeted interventions, the adjusted mortality was comparable with that of non-Indigenous Australian patients (mortality ratio $0.80,95 \%$ CI $0.51-1.23)^{259}$.

\section{Monitoring and reporting of HD outcomes across the world}

Monitoring and reporting of HD outcomes, as well as data sharing with the general public and wider research community, vary greatly between and within countries. In a systematic review of the scope and consistency of outcomes reported in 362 RCTs conducted in adults receiving $\mathrm{HD}$, the five most commonly reported outcome domains were unvalidated surrogate outcomes (for example, serum phosphate concentration, dialysis adequacy, anaemia, markers of inflammation and/or oxidative stress, and serum calcium concentration), whereas clinical outcomes such as mortality (20\%) and CVD (12\%), patient-reported outcomes such as quality of life (9\%), and fatigue or energy levels (10\%), were reported much less frequently ${ }^{17}$. Most outcome domains $(60 \%)$ had $>10$ different outcome measures, which in general had variable definitions, methods of aggregation, metrics and time frames of measurement ${ }^{17}$. Similarly, monitoring and reporting of surrogate outcomes (such as small solute clearance, haemoglobin level, blood pressure and bone mineral markers) were considerably more common than that of clinical outcomes (patient and technique survival) or patient-reported outcomes in HD clinical practice around the world ${ }^{14}$ (FIG. 4). A review of outcome data from 48 registries around the world revealed that only $66 \%$ had available data on mortality, survival, hospitalizations or complications, whereas the majority reported some form of laboratory-based data ${ }^{41}$. This variation in the choice and frequency with which HD indicators are monitored and reported is affected by country income level. For example, most HICs measure and report small solute clearance $(87 \%)$ and bone mineral markers (85\%) almost all of the time, but only a minority of low-income countries $(28 \%$ and $17 \%$, respectively) have the capacity to report these markers in a consistent manner ${ }^{14}$. This difference widens when considering technique and patient survival, or patient-reported outcomes ${ }^{14}$.

Kidney registries have a key role in capturing variations in patient outcomes at a local, regional or national level that help to evaluate the safety and quality of patient care and facilitate the integration of evidence-based guidelines into individual treatment sites. Registries can also facilitate the conduct of pragmatic RCTs by providing a platform for case records, data collection, randomization and follow-up. Unsurprisingly, the International Society of Nephrology Global Kidney Health Atlas survey showed that only $66 \%$ of countries had dialysis registries; prevalence varied according to country income (86\% for HICs, $76 \%$ for UMICs, $51 \%$ for LMICs and $18 \%$ for LICs) $)^{260}$. Consequently, substantial knowledge gaps exist in how dialysis outcomes are monitored and accounted for in lower income regions of the world.

Although practice differences between individual units explain much of the variability in HD outcome monitoring and reporting, the availability of robust health information systems - from facility databases to national registries - that are capable of measuring and reporting on quality dialysis indicators is an important limiting factor in many parts of the world ${ }^{260}$. This widespread under-capturing, and incomplete and inconsistent reporting of patient-important HD outcome measures represents a substantial barrier to continuous quality improvement in $\mathrm{HD}$ and prevents benchmarking comparisons of outcomes between units, centres and regions. To ensure that every patient has access to equitable, high-quality dialysis care that directly addresses their physical, psychological and lifestyle needs, routine monitoring and reporting of facility outcomes and patient-centred care are needed. At a minimum, these parameters should include patient data

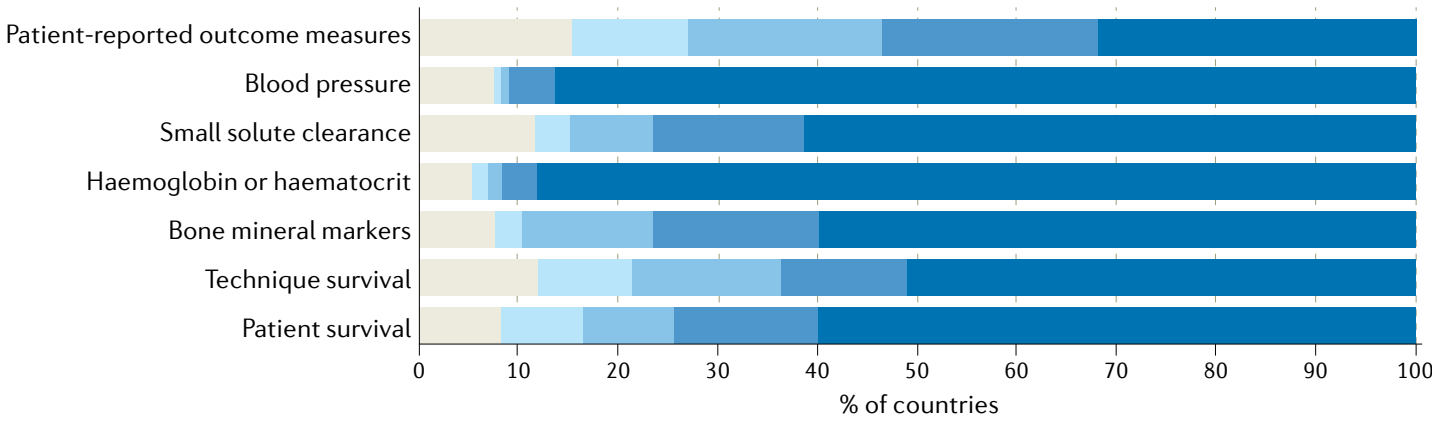

\% of monitoring centres within a country: $\quad 0 \% \quad 1-10 \% \quad 11-50 \% \quad \square 1-75 \% \square>75 \%$

Fig. 4 | Haemodialysis quality indicators monitored and reported in 144 countries. The figure depicts data from the Global Kidney Health Atlas with 144 countries contributing data on reporting HD quality-of-care metrics. This reporting was assessed by examining the percentage proportion of centres (in each participating country) that routinely monitored and reported the outcomes or parameters (patient-reported outcome measures, blood pressure, small solute clearance, haemoglobin or haematocrit, and technique and patient survival) in a country. Adapted with permission from $\mathrm{Htay}$ et al. ${ }^{14}$, Elsevier. 
pertaining to the five SONG-HD core outcomes (that is, vascular access problems, dialysis adequacy, fatigue, CVD and mortality ${ }^{110}$ ) alongside other important process of care metrics, such as quality of communications and caring by physicians and nurses, and quality of dialysis centre care and operations, as outlined in the various dialysis guidelines and reviews ${ }^{261}$. Finally, regular monitoring of patient-reported outcomes and experience measures, such as HR-QOL, is crucial to identifying and understanding what is directly relevant to patients and their caregivers ${ }^{262}$.

\section{Conclusions}

$\mathrm{HD}$ is the dominant form of dialysis worldwide. Although substantial improvements have been observed in HD delivery and outcomes over the last decade, patients receiving this treatment still experience poor quality of life and their symptom, financial, morbidity and mortality burdens are unacceptably high (TABLE 1). Moreover, the outcomes of patients on HD are variably monitored and reported, and are highly heterogeneous between regions, countries, centres and different segments of the population. Potential reasons for variations in reported outcomes include the use of variable outcome definitions, variable practices and disparities in the health care provided to vulnerable and disadvantaged populations (including First Nations peoples and people at the extremes of age).
Across the globe, variability in the outcomes reported for patients treated with HD has multiple causes and is mostly influenced by the different approaches to outcome definitions (for example, hospitalizations or infection rates might be defined and/or reported differently across settings), population heterogeneity (for example, age, sex, race and comorbid illness burden), health system factors (for example, organization of care delivery and mechanisms, funding structures, health information system availability, policy regarding dialysis modality selection and workforce), competing risks that affect patient attrition and survival on $\mathrm{HD}$ (for example, high transplantation rates will lead to a proportionally less healthy cohort remaining on $\mathrm{HD}$ ) and also variations across settings regarding clinical practice culture (for example, HD catheter use and infection control protocols) within and across countries. These stem from a lack of globally accepted standards and/or benchmarks (and tools to collate the data in the form of registries), which complicates the comparisons of data concerning quality standards for $\mathrm{HD}$ across settings within countries and regionally. The establishment of kidney registries that collect a variety of clinical and patient-reported outcomes using harmonized definitions is therefore crucial to improve the outcomes of people on $\mathrm{HD}$ and to achieve continuous quality improvement.

Published online 22 February 2022
1. Couser, W. G. Remuzzi, G., Mendis, S. \& Tonelli, M. The contribution of chronic kidney disease to the global burden of major noncommunicable diseases. Kidney Int. 80, 1258-1270 (2011).

2. Neuen, B. L., Chadban, S. J., Demaio, A. R Johnson, D. W. \& Perkovic, V. Chronic kidney disease and the global NCDs agenda. BMJ Glob. Health 2 , e000380 (2017)

3. Jager, K. J. \& Fraser, S. D. S. The ascending rank of chronic kidney disease in the global burden of disease study. Nephrol. Dial. Transpl. 32, ii 121-ii 128 (2017).

4. Carney, E. F. The impact of chronic kidney disease on global health. Nat. Rev. Nephrol. 16, 251 (2020).

5. Jager, K. J. et al. A single number for advocacy and communication-worldwide more than 850 million individuals have kidney diseases. Kidney Int. 96, 1048-1050 (2019).

6. Foreman, K. J. et al. Forecasting life expectancy, years of life lost, and all-cause and cause-specific mortality for 250 causes of death: reference and alternative scenarios for 2016-40 for 195 countries and territories. Lancet 392, 2052-2090 (2018).

7. GBD Chronic Kidney Disease Collaboration. Global, regional, and national burden of chronic kidney disease, 1990-2017: a systematic analysis for the Global Burden of Disease Study 2017. Lancet 395 , 709-733 (2020)

8. Levey, A. S. et al. Nomenclature for kidney function and disease: report of a Kidney Disease: Improving Global Outcomes (KDIGO) Consensus Conference. Kidney Int. 97, 1117-1129 (2020).

9. Kidney Disease: Improving Global Outcomes (KDICO) \& CKD-MBD Work Group. KDIGO clinical practice guidelines for the prevention, diagnosis, evaluation, and treatment of Chronic Kidney Disease-Mineral and Bone Disorder (CKD-MBD). Kidney Disease: Improving Global Outcomes (KDIGO). Kidney Int. Suppl. https:// doi.org/10.1038/ki.2009.188 (2009).

10. Pecoits-Filho, R. et al. Capturing and monitoring global differences in untreated and treated end-stage kidney disease, kidney replacement therapy modality, and outcomes. Kidney Int. Suppl. 10, e3-e9 (2020).

11. Liyanage, T. et al. Worldwide access to treatment for end-stage kidney disease: a systematic review. Lancet 385, 1975-1982 (2015)

12. Bello, A. K. et al. Assessment of global kidney health care status. JAMA 317, 1864-1881 (2017).

13. Bello, A. K. et al. Status of care for end stage kidney disease in countries and regions worldwide: international cross sectional survey. BMJ 367, 15873 (2019).

14. Htay, H. et al. Hemodialysis use and practice patterns: an international survey study. Am. J. Kidney Dis. 77. 326-335.e321 (2021)

15. Himmelfarb, J, Vanholder R, Mehrotra, R \& Tonelli, M. The current and future landscape of dialysis. Nat. Rev. Nephrol. 16, 573-585 (2020).

16. Li, H., Xie, L., Yang, J. \& Pang, X. Symptom burden amongst patients suffering from end-stage renal disease and receiving dialysis: a literature review. Int. J. Nurs. Sci. 5, 427-431 (2018).

17. Sautenet, B. et al. Scope and consistency of outcomes reported in randomized trials conducted in adults receiving hemodialysis: a systematic review. Am. J. Kidney Dis. 72, 62-74 (2018).

18. Sola, L. et al. Development of a framework for minimum and optimal safety and quality standards for hemodialysis and peritoneal dialysis. Kidney Int. Suppl. (2011) 10, e55-e62 (2020).

19. International Society of Nephrology (ISN). ISN Framework for Developing Dialysis Programs in low-resource settings. International Society of Nephrology, Brussels, Belgium, https://www.theisn. org/wp-content/uploads/2021/03/ISN-FrameworkDialysis-Report-HIRES.pdf (2021)

20. Hodsman, A., Ben-Shlomo, Y., Roderick, P. \& Tomson, C. R. The 'centre effect' in nephrology: what do differences between nephrology centres tell us about clinical performance in patient management? Nephron Clin. Pract. 119, c10-c17; discussion c17, (2011).

21. Robinson, B. M., Bieber, B., Pisoni, R. L. \& Port, F. K. Dialysis Outcomes and Practice Patterns Study (DOPPS): its strengths, limitations, and role in informing practices and policies. Clin. J. Am. Soc. Nephrol. 7 1897-1905 (2012)

22. Tong, A. et al. Establishing core outcome domains in hemodialysis: report of the standardized outcomes in nephrology-hemodialysis (SONG-HD) Consensus Workshop. Am. J. Kidney Dis. 69, 97-107 (2017).

23. Flythe, J. E. et al. Symptom prioritization among adults receiving in-center hemodialysis: a mixed methods study. Clin. J. Am. Soc. Nephrol. 13 735-745 (2018)

24. Urquhart-Secord, R. et al. Patient and caregiver priorities for outcomes in hemodialysis: an internationa nominal group technique study. Am. J. Kidney Dis. 68, 444-454 (2016)
25. Evangelidis, N. et al. Standardized Outcomes in Nephrology-Hemodialysis (SONG-HD) Initiative: developing a set of core outcomes for trials in hemodialysis: an international Delphi survey. Am. J. Kidney Dis. 70, 464-475 (2017).

26. Viecelli, A. K. et al. Report of the Standardized Outcomes in Nephrology-Hemodialysis (SONG-HD) Consensus Workshop on establishing a core outcome measure for hemodialysis vascular access. Am. J. Kidney Dis. 71, 690-700 (2018).

27. O'Lone, E. et al. Establishing core cardiovascular outcome measures for trials in hemodialysis: report of an international consensus workshop. Am. J. Kidney Dis. 76, 109-120 (2020).

28. Ju, A. et al. Validation of a core patient-reported outcome measure for fatigue in patients receiving hemodialysis: the SONG-HD fatigue instrument. Clin. J. Am. Soc. Nephrol. 15, 1614-1621 (2020).

29. Thygesen, K. et al. Fourth universal definition of myocardial infarction (2018). Circulation 138 e618-e651 (2018).

30. Nordio, M. et al. Survival in patients treated by long-term dialysis compared with the general population. Am. J. Kidney Dis. 59, 819-828 (2012).

31. Marshall, M. R. The benefit of early survival on PD versus HD-Why this is (still) very important. Perit. Dial. Int. 40, 405-418 (2020).

32. Collins, A. J. et al. Mortality risks of peritoneal dialysis and hemodialysis. Am. J. Kidney Dis. 34, 1065-1074 (1999).

33. Fenton, S. S. et al. Hemodialysis versus peritoneal dialysis: a comparison of adjusted mortality rates. Am. J. Kidney Dis. 30, 334-342 (1997).

34. Yu, X., Fan, L., Marshall, M. R. Primary results of the quality of life in peritoneal dialysis and conventional in-center hemodialysis (China O) study: a prospective, randomized, open-label, multicenter, non-inferiority trial. [abstract TH-PO1149]. ASN Kidney Week https://www.asn-online.org/education/kidneyweek/ 2018/program-abstract. aspx? controlld=3064979 (2018).

35. Korevaar, J. C. et al. Effect of starting with hemodialysis compared with peritoneal dialysis in patients new on dialysis treatment: a randomized controlled trial. Kidney Int. 64, 2222-2228 (2003).

36. Morton, R. L., Tong, A., Howard, K., Snelling, P. \& Webster, A. C. The views of patients and carers in treatment decision making for chronic kidney disease: systematic review and thematic synthesis of qualitative studies. BMJ 340, c112 (2010). 
37. Bradbury, B. D. et al. Predictors of early mortality among incident US hemodialysis patients in the Dialysis Outcomes and Practice Patterns Study (DOPPS). Clin. J. Am. Soc. Nephrol. 2, 89-99 (2007).

38. Robinson, B. M. et al. Worldwide, mortality risk is high soon after initiation of hemodialysis. Kidney Int. $\mathbf{8 5}$ 158-165 (2014)

39. United States Renal Data System. 2020 USRDS Annual Data Report: Epidemiology of kidney disease in the United States. (National Institutes of Health, National Institute of Diabetes and Digestive and Kidney Diseases, Bethesda, MD, 2020).

40. ANZDATA Registry. 43rd Report, Chapter 4: Haemodialysis. Australia and New Zealand Dialysis and Transplant Registry (ANZDATA, Adelaide, Australia, 2020)

41. Liu, F. X., Rutherford, P., Smoyer-Tomic, K., Prichard, S. ¿ Laplante, S. A global overview of renal registries: a systematic review. BMC Nephrol. 16, 31 (2015).

42. Goodkin, D. A. et al. Association of comorbid conditions and mortality in hemodialysis patients in Europe, Japan, and the United States: the Dialysis Outcomes and Practice Patterns Study (DOPPS). J. Am. Soc. Nephrol. 14, 3270-3277 (2003).

43. Khazaei, S. et al. Survival rate and predictors of mortality among hemodialysis patients in West of Iran, 1996-2015. Int. J. Prev. Med. 9, 113 (2018)

44. Msaad, R. et al. Predictors of mortality in hemodialysis patients. Pan Afr. Med. J. 33, 61 (2019).

45. Jardine, T., Wong, E., Steenkamp, R., Caskey, F. J. \& Davids, M. R. Survival of South African patients on renal replacement therapy. Clin. Kidney J. 13 782-790 (2020).

46. Herrera-Añazco, P., Benites-Zapata, V., Hernandez, A. V., Mezones-Holguin, E. \& Silveira-Chau, M. Mortality in patients with chronic kidney disease undergoing hemodialysis in a public hospital of Peru. J. Bras. Nefrol. 37, 192-197 (2015)

47. Chertow, G. M. et al. In-center hemodialysis six times per week versus three times per week. N. Engl. J. Med 363, 2287-2300 (2010).

48. Marshall, M. R., Byrne, B. G., Kerr, P. G. \& McDonald, S. P. Associations of hemodialysis dose and session length with mortality risk in Australian and New Zealand patients. Kidney Int. 69, 1229-1236 (2006).

49. Eknoyan, G. et al. Effect of dialysis dose and membrane flux in maintenance hemodialysis. N. Engl. J. Med. 347, 2010-2019 (2002).

50. Gansevoort, R. T. et al. Chronic kidney disease and cardiovascular risk: epidemiology, mechanisms, and prevention. Lancet 382, 339-352 (2013)

51. Thompson, S. et al. Cause of death in patients with reduced kidney function. J. Am. Soc. Nephrol. 26 , 2504-2511 (2015)

52. Johnson, D. W. et al. Association of dialysis modality and cardiovascular mortality in incident dialysis patients. Clin. J. Am. Soc. Nephrol. 4, 1620-1628 (2009).

53. Takeda, K. et al. Sudden death in chronic dialysis patients. Nephrol. Dial. Transpl. 12, 952-955 (1997).

54. Saran, R. et al. US Renal Data System 2018 Annual Data Report: Epidemiology of Kidney Disease in the United States. Am. J. Kidney Dis. 73, A7-A8 (2019).

55. Genovesi, S. et al. Sudden cardiac death in dialysis patients: different causes and management strategies. Nephrol. Dial. Transpl. 36, 396-405 (2021).

56. Krishnasamy, R. et al. Daily variation in death in patients treated by long-term dialysis: comparison of in-center hemodialysis to peritoneal and home hemodialysis. Am. J. Kidney Dis. 61, 96-103 (2013)

57. Jadoul, M. et al. Modifiable practices associated with sudden death among hemodialysis patients in the Dialysis Outcomes and Practice Patterns Study. Clin. J. Am. Soc. Nephrol. 7, 765-774 (2012).

58. Jankowski, J., Floege, J., Fliser, D., Böhm, M. \& Marx, N. Cardiovascular disease in chronic kidney disease: pathophysiological insights and therapeutic options. Circulation 143, 1157-1172 (2021).

59. Roehm, B. \& Weiner, D. E. Blood pressure targets and kidney and cardiovascular disease: same data but discordant guidelines. Curr. Opin. Nephrol. Hypertens. 28, 245-250 (2019)

60. Patel, A. et al. Intensive blood glucose control and vascular outcomes in patients with type 2 diabetes. N. Engl. J. Med. 358, 2560-2572 (2008).

61. Ishida, J. H. et al. Understanding and overcoming the challenges related to cardiovascular trials involving patients with kidney disease. Clin. J. Am. Soc. Nephrol 16, 1435-1444 (2021).
62. Konstantinidis, I. et al. Representation of patients with kidney disease in trials of cardiovascular interventions: an updated systematic review. JAMA Intern. Med. 176, 121-124 (2016).

63. Maini, R. et al. Persistent underrepresentation of kidney disease in randomized, controlled trials of cardiovascular disease in the contemporary era. J. Am. Soc. Nephrol. 29, 2782-2786 (2018).

64. Taylor, M. J. et al. "You know your own fistula, it becomes a part of you" - patient perspectives on vascular access: a semistructured interview study. Hemodial. Int. 20, 5-14 (2016).

65. Manns, B. et al. Establishment and maintenance of vascular access in incident hemodialysis patients: a prospective cost analysis. J. Am. Soc. Nephrol. 16, 201-209 (2005)

66. Weinhandl, E. D., Nieman, K. M., Gilbertson, D. T. $\S$ Collins, A. J. Hospitalization in daily home hemodialysis and matched thrice-weekly in-center hemodialysis patients. Am. J. Kidney Dis. 65, 98-108 (2015).

67. Ravani, P. et al. Associations between hemodialysis access type and clinical outcomes: a systematic review. J. Am. Soc. Nephrol. 24, 465-473 (2013).

68. Jones, S. M., Ravani, P., Hemmelgarn, B. R., Muruve, D. $\&$ Macrae, J. M. Morphometric and biological characterization of biofilm in tunneled hemodialysis catheters. Am. J. Kidney Dis. 57, 449-455 (2011).

69. Vascular Access 2006 Work Group. Clinical practice guidelines for vascular access. Am. J. Kidney Dis. 48, S176-S247 (2006).

70. Allon, M. Vascular access for hemodialysis patients: new data should guide decision making. Clin. J. Am. Soc. Nephrol. 14, 954-961 (2019)

71. MacRae, J. M. et al. Arteriovenous vascular access selection and evaluation. Can. J. Kidney Health Dis. 3, 2054358116669125 (2016)

72. Lok, C. E. et al. KDOQI Clinical Practice Guideline for Vascular Access: 2019 Update. Am. J. Kidney Dis. 75, S1-S164 (2020)

73. $\mathrm{Ng}$, S. et al. Center-effect of incident hemodialysis vascular access use: analysis of a bi-national registry. Kidney360 2, 674-683 (2021).

74. Pisoni, R. L. et al. International differences in the location and use of arteriovenous accesses created for hemodialysis: results from the dialysis outcomes and practice patterns study (DOPPS). Am. J. Kidney Dis. 71, 469-478 (2018)

75. Centers for Medicare \& Medicaid Services. ESRD Quality Incentive Program, https://www.cms.gov/ Medicare/Quality-Initiatives-Patient-AssessmentInstruments/ESRDQIP (2020).

76. MacRae, J. M., Pandeya, S., Humen, D. P., Krivitski, N. $\&$ Lindsay, R. M. Arteriovenous fistula-associated high-output cardiac failure: a review of mechanisms. Am. J. Kidney Dis. 43, e17-e22 (2004)

77. Yu, S. H. et al. Hemodialysis-related steal syndrome predictive factors and response to treatment with the distal revascularization-interval ligation procedure. Ann. Vasc. Surg. 22, 210-214 (2008)

78. Naqvi, S. B. \& Collins, A. J. Infectious complications in chronic kidney disease. Adv. Chronic Kidney Dis. 13 199-204 (2006)

79. Nguyen, D. B. et al. National Healthcare Safety Network (NHSN) Dialysis Event Surveillance Report for 2014. Clin. J. Am. Soc. Nephrol. 12, 1139-1146 (2017).

80. Shingarev, R., Barker-Finkel, J. \& Allon, M. Natural history of tunneled dialysis catheters placed for hemodialysis initiation. J. Vasc. Interv. Radiol. 24, 1289-1294 (2013).

81. Thompson, S. et al. Catheter-related blood stream infections in hemodialysis patients: a prospective cohort study. BMC Nephrol. 18, 357 (2017).

82. Yap, H. Y. et al. Catheter-related complications and survival among incident hemodialysis patients in Singapore. J. Vasc. Access 19, 602-608 (2018)

83. Delistefani, F., Wallbach, M., Müller G. A Koziolek, M. J. \& Grupp, C. Risk factors for catheterrelated infections in patients receiving permanent dialysis catheter. BMC Nephrol. 20, 199 (2019).

84. Samani, S., Saffari, M., Charkhchian, M. \& Khaki, A. Incidence and risk factors of bloodstream catheter-related infections in hemodialysis patients. Comp. Clin. Path. 24, 275-279 (2015).

85. Sahli, F., Feidjel, R. \& Laalaoui, R. Hemodialysis catheter-related infection: rates, risk factors and pathogens. J. Infect. Public Health 10, 403-408 (2017).

86. Barraclough, K. A., Hawley, C. M., Playford, E. G. \& Johnson, D. W. Prevention of access-related infection in dialysis. Expert Rev. Anti Infect. Ther. 7, 1185-1200 (2009).
87. Nguyen, D. B., Bixler, D. \& Patel, P. R. Transmission of hepatitis $C$ virus in the dialysis setting and strategies for its prevention. Semin. Dial. 32, 127-134 (2019).

88. Goodkin, D. A. et al. Mortality, hospitalization, and quality of life among patients with hepatitis $C$ infection on hemodialysis. Clin. J. Am. Soc. Nephrol. 12, 287-297 (2017)

89. Fissell, R. B. et al. Patterns of hepatitis C prevalence and seroconversion in hemodialysis units from three continents: the DOPPS. Kidney Int. 65, 2335-2342 (2004).

90. Ashkani-Esfahani, S Alavian, S. M \&

Salehi-Marzijarani, M. Prevalence of hepatitis C virus infection among hemodialysis patients in the Middle-East: a systematic review and meta-analysis. World J. Gastroenterol. 23, 151-166 (2017).

91. Davids, M. R., Jardine, T., Marais, N. \& Jacobs, J. C. South African Renal Registry Annual Report 2016. Afr. J. Nephrol. 21, 61-72 (2018).

92. Boima, V. et al. The Ghana Renal Registry - a first annual report. Afr. J. Nephrol. 24, 19-24 (2021).

93. Adane, T. \& Getawa, S. The prevalence and associated factors of hepatitis $B$ and $C$ virus in hemodialysis patients in Africa: a systematic review and meta-analysis. PLoS One 16, e0251570 (2021).

94. Burdick, R. A. et al. Patterns of hepatitis B prevalence and seroconversion in hemodialysis units from three continents: the DOPPS. Kidney Int. 63, 2222-2229 (2003).

95. El Sayed, N. M. et al. Epidemic transmission of human immunodeficiency virus in renal dialysis centers in Egypt. J. Infect. Dis. 181, 91-97 (2000)

96. Berman, S. J. et al. Burden of infection in patients with end-stage renal disease requiring long-term dialysis. Clin. Infect. Dis. 39, 1747-1753 (2004)

97. Sibbel, S., Sato, R., Hunt, A., Turenne, W. \& Brunelli, S. M. The clinical and economic burden of pneumonia in patients enrolled in Medicare receiving dialysis: a retrospective, observational cohort study. BMC Nephrol. 17, 199 (2016).

98. Bond, T. C., Spaulding, A. C., Krisher, J. \& McClellan, W. Mortality of dialysis patients according to influenza and pneumococcal vaccination status. Am. J. Kidney Dis. 60, 959-965 (2012)

99. Nopsopon, T. et al. Covid-19 in end-stage renal disease patients with renal replacement therapies: a systematic review and meta-analysis. PLoS Negl. Trop. Dis. 15, e0009156 (2021).

100. Daratha, K. B. et al. Risks of subsequent hospitalization and death in patients with kidney disease. Clin. J. Am. Soc. Nephrol. 7, 409-416 (2012).

101. Rocco, M. V., Soucie, J. M., Reboussin, D. M. \& McClellan, W. M. Risk factors for hospital utilization in chronic dialysis patients. Southeastern Kidney Council (Network 6). J. Am. Soc. Nephrol. 7, 889-896 (1996).

102. Schouten, R. W. et al. Anxiety symptoms, mortality, and hospitalization in patients receiving maintenance dialysis: a cohort study. Am. J. Kidney Dis. 74, 158-166 (2019)

103. McAdams-DeMarco, M. A. et al. Frailty as a novel predictor of mortality and hospitalization in individuals of all ages undergoing hemodialysis. J. Am. Geriatr. Soc 61, 896-901 (2013).

104. Banerjee, T. et al. Free and total p-cresol sulfate levels and infectious hospitalizations in hemodialysis patients in CHOICE and HEMO. Medicine 96, e5799 (2017).

105. Mandai, S. et al. Lower serum sodium level predicts higher risk of infection-related hospitalization in maintenance hemodialysis patients: an observational cohort study. BMC Nephrol. 14, 276 (2013).

106. Szuck, P., Führ, L. M., Garcia, M. F., Silva, A. T. D. $\&$ Wazlawik, E. Association between nutritional indicators and risk of hospitalization among hemodialysis patients. Rev. Nutr. 29, 317-327 (2016).

107. Rayner, H. C. et al. Mortality and hospitalization in haemodialysis patients in five European countries: results from the Dialysis Outcomes and Practice Patterns Study (DOPPS). Nephrol. Dial. Transpl. 19 108-120 (2004)

108. Molnar, A. O. et al. Hospitalizations in dialysis patients in Canada: a national cohort study. Can. J. Kidney Health Dis. 5, 2054358118780372 (2018)

109. Nath, J. D. \& Kashem, A. Etiology and frequency of hospital admissions in maintenance hemodialysis patients in chronic kidney disease. Saudi J. Kidney Dis. Transpl. 30, 508-512 (2019).

110. Evangelidis, N. et al. Developing a set of core outcomes for trials in hemodialysis: an international Delphi survey. Am. J. Kidney Dis. 70, 464-475 (2017). 
111. Ok, E. et al. Mortality and cardiovascular events in online haemodiafiltration (OL-HDF) compared with high-flux dialysis: results from the Turkish OL-HDF Study. Nephrol. Dial. Transpl. 28, 192-202 (2013)

112. Maduell, F. et al. High-efficiency postdilution online hemodiafiltration reduces all-cause mortality in hemodialysis patients. J. Am. Soc. Nephrol. 24 487-497 (2013)

113. Mathew, A. et al. Mortality and hospitalizations in intensive dialysis: a systematic review and meta-analysis. Can. J. Kidney Health Dis. 5 2054358117749531 (2018).

114. Lin, Y. F. et al. Comparison of residual renal function in patients undergoing twice-weekly versus three-times-weekly haemodialysis. Nephrology $\mathbf{1 4}$, 59-64 (2009).

115. Hasan, O. et al. Hospital readmission in general medicine patients: a prediction model. J. Gen. Intern. Med. 25, 211-219 (2010)

116. Wingard, R. L. et al. Right TraC ${ }^{\text {Th }}$ post-hospitalization care transitions program to reduce readmissions for hemodialysis patients. Am. J. Nephrol. 45, 532-539 (2017).

117. Golestaneh, L. Decreasing hospitalizations in patients on hemodialysis: time for a paradigm shift. Semin. Dial. 31, 278-288 (2018)

118. Mathew, A. T., Strippoli, G. F., Ruospo, M. \& Fishbane, S. Reducing hospital readmissions in patients with end-stage kidney disease. Kidney Int. 88, 1250-1260 (2015)

119. O'Lone, E. et al. Cognition in people with end-stage kidney disease treated with hemodialysis: a systematic review and meta-analysis. Am. J. Kidney Dis. 67, 925-935 (2016)

120. van Zwieten, A. et al. Prevalence and patterns of cognitive impairment in adult hemodialysis patients: the COGNITIVE-HD study. Nephrol. Dial. Transpl. 33, 1197-1206 (2018)

121. Kurella Tamura, M. et al. Effect of more frequent hemodialysis on cognitive function in the frequent hemodialysis network trials. Am. J. Kidney Dis. 61, 228-237 (2013)

122. Guerraoui, A. et al. Patient-reported outcome measures in hemodialysis patients: results of the first multicenter cross-sectional ePROMs study in France. BMC Nephrol. 22, 357 (2021).

123. Gregg, L. P., Bossola, M., Ostrosky-Frid, M. \& Hedayati, S. S. Fatigue in CKD: epidemiology, pathophysiology, and treatment. Clin. J. Am. Soc. Nephrol. 16, 1445-1455 (2021).

124. Lee, K. A., Hicks, G. \& Nino-Murcia, G. Validity and reliability of a scale to assess fatigue. Psychiatry Res. 36, 291-298 (1991)

125. Jhamb, M. et al. Correlates and outcomes of fatigue among incident dialysis patients. Clin. J. Am. Soc. Nephrol. 4, 1779-1786 (2009).

126. Leinau, L., Murphy, T. E., Bradley, E. \& Fried, T Relationship between conditions addressed by hemodialysis guidelines and non-ESRD-specific conditions affecting quality of life. Clin. J. Am. Soc Nephrol. 4, 572-578 (2009).

127. Jhamb, M. et al. Impact of fatigue on outcomes in the hemodialysis (HEMO) study. Am. J. Nephrol. 33 515-523 (2011)

128. Debnath, S. et al. Fatigue characteristics on dialysis and non-dialysis days in patients with chronic kidney failure on maintenance hemodialysis. BMC Nephrol. 22, 112 (2021)

129. Jhamb, M., Weisbord, S. D., Steel, J. L. \& Unruh, M. Fatigue in patients receiving maintenance dialysis: a review of definitions, measures, and contributin factors. Am. J. Kidney Dis. 52, 353-365 (2008).

130. Weisbord, S. D. et al. Development of a symptom assessment instrument for chronic hemodialysis patients: the Dialysis Symptom Index. J. Pain Symptom Manag. 27, 226-240 (2004).

131. Webster, K., Cella, D. \& Yost, K. The Functional Assessment of Chronic Illness Therapy (FACIT) Measurement System: properties, applications, and interpretation. Health Qual. Life Outcomes 1 79 (2003)

132. Bruera, E., Kuehn, N., Miller, M. J., Selmser, P. \& Macmillan, K. The Edmonton Symptom Assessment System (ESAS): a simple method for the assessment of palliative care patients. J. Palliat. Care 7, 6-9 (1991).

133. Ware, J. E. Jr. \& Sherbourne, C. D. The MOS 36-item short-form health survey (SF-36). I. Conceptual framework and item selection. Med. Care 30 , 473-483 (1992)

134. Ju, A. et al. Identifying dimensions of fatigue in haemodialysis important to patients, caregivers and health professionals: an international survey. Nephrology 25, 239-247 (2020).

135. Dantzer, R. \& Kelley, K. W. Twenty years of research on cytokine-induced sickness behavior. Brain Behav. Immun. 21, 153-160 (2007).

136. Bossola, M., Luciani, G., Giungi, S. \& Tazza, L. Anorexia, fatigue, and plasma interleukin- 6 levels in chronic hemodialysis patients. Ren. Fail. 32, 1049-1054 (2010)

137. Hopkins, S. J. Central nervous system recognition of peripheral inflammation: a neural, hormonal collaboration. Acta Biomed. 78, 231-247 (2007)

138. Bossola, M., Vulpio, C. \& Tazza, L. Fatigue in chronic dialysis patients. Semin. Dial. 24, 550-555 (2011)

139. Puetz, T. W. Physical activity and feelings of energy and fatigue: epidemiological evidence. Sports Med. 36, 767-780 (2006)

140. Sovatzidis, A. et al. Intradialytic cardiovascular exercise training alters redox status, reduces inflammation and improves physical performance in patients with chronic kidney disease. Antioxidants 9 868 (2020).

141. Huang, M. et al. Exercise training and outcomes in hemodialysis patients: systematic review and meta-analysis. Am. J. Nephrol. 50, 240-254 (2019).

142. Morton, R. L. et al. Factors influencing patient choice of dialysis versus conservative care to treat end-stage kidney disease. CMAJ 184, E277-E283 (2012).

143. Blake, C., Codd, M. B., Cassidy, A. \& O'Meara, Y. M Physical function, employment and quality of life in end-stage renal disease. J. Nephrol. 13, 142-149 (2000).

144. Nie, Y. et al. Changes in employment status prior to initiation of maintenance hemodialysis in the USA from 2006 to 2015. Clin. Kidney J. 13, 434-441 (2020).

145. Waraich, P., Goldner, E. M., Somers, J. M. \& Hsu, L. Prevalence and incidence studies of mood disorders: a systematic review of the literature. Can. J. Psychiatry 49, 124-138 (2004)

146. Palmer, S. et al. Prevalence of depression in chronic kidney disease: systematic review and meta-analysis of observational studies. Kidney Int. 84, 179-191 (2013).

147. Lopes, A. A. et al. Screening for depression in hemodialysis patients: associations with diagnosis, treatment, and outcomes in the DOPPS. Kidney Int 66, 2047-2053 (2004)

148. Bautovich, A., Katz, I., Smith, M., Loo, C. K. \& Harvey, S. B. Depression and chronic kidney disease: a review for clinicians. Aust. N. Z. J. Psychiatry 48, 530-541 (2014)

149. Harvey, S. B. \& Ismail, K. Psychiatric aspects of chronic physical disease. Medicine 36, 471-474 (2008).

150. Koo, J. R. et al. Association of depression with malnutrition in chronic hemodialysis patients. Am. J. Kidney Dis. 41, 1037-1042 (2003).

151. Rosenthal Asher, D., Ver Halen, N. \& Cukor, D. Depression and nonadherence predict mortality in hemodialysis treated end-stage renal disease patients. Hemodial. Int. 16, 387-393 (2012).

152. Weisbord, S. D. et al. Prevalence, severity, and importance of physical and emotional symptoms in chronic hemodialysis patients. J. Am. Soc. Nephrol. 16, 2487-2494 (2005)

153. Chan, R., Brooks, R., Erlich, J., Chow, J. \& Suranyi, M The effects of kidney-disease-related loss on long-term dialysis patients' depression and quality of life: positive affect as a mediator. Clin. J. Am. Soc. Nephrol. 4, 160-167 (2009).

154. Palmer, S. C. et al. Association between depression and death in people with CKD: a meta-analysis of cohort studies. Am. J. Kidney Dis. 62, 493-505 (2013).

155. Lopes, A. A. et al. Depression as a predictor of mortality and hospitalization among hemodialysis patients in the United States and Europe. Kidney Int 62, 199-207 (2002)

156. Kimmel, P. L. Psychosocial factors in adult end-stage renal disease patients treated with hemodialysis: correlates and outcomes. Am. J. Kidney Dis. 35, S132-S140 (2000)

157. Cukor, D., Peterson, R. A., Cohen, S. D. \& Kimmel, P. L. Depression in end-stage renal disease hemodialysis patients. Nat. Clin. Pract. Nephrol. 2, 678-687 (2006).

158. Kondo, K., Antick, J. R., Ayers, C. K., Kansagara, D. $\S$ Chopra, P. Depression screening tools for patients with kidney failure: a systematic review. Clin. J. Am. Soc. Nephrol. 15, 1785-1795 (2020).

159. Friedli, K. et al. Sertraline versus placebo in patients with major depressive disorder undergoing hemodialysis: a randomized, controlled feasibility trial. Clin. J. Am. Soc. Nephrol. 12, 280-286 (2017)

160. Blumenfield, M. et al. Fluoxetine in depressed patients on dialysis. Int. J. Psychiatry Med. 27, 71-80 (1997).

161. Natale, P. et al. Psychosocial interventions for preventing and treating depression in dialysis patients. Cochrane Database Syst. Rev. 12, CD004542 (2019).

162. Huang, C. W. et al. Prevalence and risk factors for elevated anxiety symptoms and anxiety disorders in chronic kidney disease: A systematic review and meta-analysis. Gen. Hosp. Psychiatry 69, 27-40 (2021).

163. Simões, E. S. A. C., Miranda, A. S., Rocha, N. P. \& Teixeira, A. L. Neuropsychiatric disorders in chronic kidney disease. Front. Pharmacol. 10, 932 (2019).

164. Lerma, A. et al. Brief cognitive behavioural intervention for depression and anxiety symptoms improves quality of life in chronic haemodialysis patients. Psychol. Psychother. 90, 105-123 (2017).

165. Kobrin, S. M. \& Berns, J. S. Quinine - a tonic too bitter for hemodialysis-associated muscle cramps? Semin. Dial. 20, 396-401 (2007).

166. Oguma, S. et al. Biotin ameliorates muscle cramps of hemodialysis patients: a prospective trial. Tohoku J. Exp. Med. 227, 217-223 (2012).

167. Canzanello, V. J. \& Burkart, J. M. Hemodialysisassociated muscle cramps. Semin. Dial. 5, 299-304 (1992).

168. Ipema, K. J. et al. Causes and consequences of interdialytic weight gain. Kidney Blood Press. Res. 41 710-720 (2016)

169. Ulu, S. \& Ahsen, A. Muscle cramps during hemodialysis: what can we do? New approaches for treatment and preventing. Eur. J. Gen. Pract. 12, 277-281 (2015)

170. Hyodo, T. et al. Immediate effect of Shakuyakukanzo-to on muscle cramp in hemodialysis patients. Nephron Clin. Pract. 104, c28-c32 (2006).

171. Brkovic, T., Burilovic, E. \& Puljak, L. Prevalence and severity of pain in adult end-stage renal disease patients on chronic intermittent hemodialysis: a systematic review. Patient Prefer. Adherence 10 1131-1150 (2016).

172. Davison, S. N. et al. The prevalence and severity of chronic pain in patients with chronic kidney disease: a systematic review and meta-analysis. Can. J. Kidney Health Dis. 19, 2054358121993995 (2021).

173. Davison, S. N. \& Jhangri, G. S. Impact of pain and symptom burden on the health-related quality of life of hemodialysis patients. J. Pain. Symptom Manag. 39, 477-485 (2010)

174. Davison, S. N. Pain in hemodialysis patients: prevalence, cause, severity, and management. Am. J. Kidney Dis. 42, 1239-1247 (2003)

175. Davison, S. N. Clinical pharmacology considerations in pain management in patients with advanced kidney failure. Clin. J. Am. Soc. Nephrol. 14, 917-931 (2019).

176. Tobin, D. G. et al. Opioids for chronic pain management in patients with dialysis-dependent kidney failure. Nat. Rev. Nephrol. 18, 113-128 (2022).

177. Lopes, G. B. et al. Assessment of the psychological burden associated with pruritus in hemodialysis patients using the kidney disease quality of life short form. Qual. Life Res. 21, 603-612 (2012).

178. Pisoni, R. L. et al. Pruritus in haemodialysis patients: international results from the Dialysis Outcomes and Practice Patterns Study (DOPPS). Nephrol. Dial. Transpl. 21, 3495-3505 (2006)

179. Biro, T. et al. How best to fight that nasty itch from new insights into the neuroimmunological neuroendocrine, and neurophysiological bases of pruritus to novel therapeutic approaches. Exp. Dermatol. 14, 225-240 (2005).

180. Fishbane, S., Jamal, A., Munera, C., Wen, W. \& Menzaghi, F. A phase 3 trial of difelikefalin in hemodialysis patients with pruritus. N. Engl. J. Med 382, 222-232 (2020)

181. Walters, A. S. Toward a better definition of the restless legs syndrome. The International Restless Legs Syndrome Study Group. Mov. Disord. 10, 634-642 (1995).

182. Novak, M., Mendelssohn, D., Shapiro, C. M. \& Mucsi, I. Diagnosis and management of sleep apnea syndrome and restless legs syndrome in dialysis patients. Semin. Dial. 19, 210-216 (2006).

183. Winkelman, J. W., Chertow, G. M. \& Lazarus, J. M. Restless legs syndrome in end-stage renal disease. Am. J. Kidney Dis. 28, 372-378 (1996).

184. La Manna, G. et al. Restless legs syndrome enhances cardiovascular risk and mortality in patients with end-stage kidney disease undergoing long-term haemodialysis treatment. Nephrol. Dial. Transpl. 26, 976-1983 (2011). 
185. Trenkwalder, C., Paulus, W. $\&$ Walters, A. S. The restless legs syndrome. Lancet Neurol 4 465-475 (2005).

186. Molnar, M. Z., Novak, M. \& Mucsi, I. Management of restless legs syndrome in patients on dialysis. Drugs 66, 607-624 (2006).

187. Navaneethan, S. D. et al. Prevalence and correlates of self-reported sexual dysfunction in CKD: a meta-analysis of observational studies. Am. J. Kidney Dis. 56, 670-685 (2010)

188. Vecchio, M. et al. Interventions for treating sexual dysfunction in patients with chronic kidney disease. Cochrane Database Syst. Rev. 8, CD007747 (2010).

189. Elder, S. J. et al. Sleep quality predicts quality of life and mortality risk in haemodialysis patients: results from the dialysis outcomes and practice patterns study (DOPPS). Nephrol. Dial. Transpl. 23, 998-1004 (2008).

190. Flythe, J. E. et al. Blood pressure and volume management in dialysis: conclusions from a Kidney Disease: Improving Global Outcomes (KDIGO) Controversies Conference. Kidney Int. 97, 861-876 (2020).

191. Kalantar-Zadeh, K., Kilpatrick, R. D., McAllister, C. J., Greenland, S. \& Kopple, J. D. Reverse epidemiology of hypertension and cardiovascular death in the hemodialysis population: the 58th annual fall conference and scientific sessions. Hypertension $\mathbf{4 5}$, 811-817 (2005)

192. Myers, O. B. et al. Age, race, diabetes, blood pressure, and mortality among hemodialysis patients. J. Am. Soc. Nephrol. 21, 1970-1978 (2010)

193. Jhee, J. H. et al. The optimal blood pressure target in different dialysis populations. Sci. Rep. 8, 14123 (2018).

194. Isakova, T. et al. KDOQI US Commentary on the 2017 KDIGO Clinical Practice Guideline Update for the Diagnosis, Evaluation, Prevention, and Treatment of Chronic Kidney Disease-Mineral and Bone Disorder (CKD-MBD). Am. J. Kidney Dis. 70 737-751 (2017)

195. Hedgeman, E. et al. International burden of chronic kidney disease and secondary hyperparathyroidism a systematic review of the literature and available data. Int. J. Nephrol. 2015, 184321 (2015).

196. Abdu, A., Abdu, A. \& Arogundade, F. A. Prevalence and pattern of chronic kidney disease-mineral bone disorders among hemodialysis patients in Kano, northwest Nigeria. Ann. Afr. Med. 18, 191-195 (2019).

197. Chiu, Y. W. et al. Pill burden, adherence, hyperphosphatemia, and quality of life in maintenance dialysis patients. Clin. J. Am. Soc. Nephrol. 4, 1089-1096 (2009)

198. Palmer, S. C. et al. Association of drug effects on serum parathyroid hormone, phosphorus, and calcium levels with mortality in CKD: a meta-analysis. Am. J. Kidney Dis. 66, 962-971 (2015).

199. Palmer, S. C. et al. Phosphate-binding agents in adults with CKD: a network meta-analysis of randomized trials. Am. J. Kidney Dis. 68, 691-702 (2016)

200. Haley, W. E., Roth, D. L., Howard, G. \& Safford, M. M. Caregiving strain and estimated risk for stroke and coronary heart disease among spouse caregivers: differential effects by race and sex. Stroke $\mathbf{4 1}$ 331-336 (2010)

201. Adelman, R. D., Tmanova, L. L., Delgado, D., Dion, S. \& Lachs, M. S. Caregiver burden: a clinical review. JAMA 311, 1052-1060 (2014).

202. Belasco, A., Barbosa, D., Bettencourt, A. R., Diccini, S $\&$ Sesso, R. Quality of life of family caregivers of elderly patients on hemodialysis and peritoneal dialysis. Am. J. Kidney Dis. 48, 955-963 (2006)

203. DePasquale, N. et al. Family members' experiences with dialysis and kidney transplantation. Kidney Med. 1, 171-179 (2019)

204. Tong, A. et al. The beliefs and expectations of patients and caregivers about home haemodialysis: an interview study. BMJ Open 3, e002148 (2013).

205. Zhang, R. et al. Burden in primary family caregivers caring for uremic patients on maintenance peritoneal dialysis. Perit. Dial. Int. 40, 556-562 (2020).

206. Kari, J. A., Alzahrany, M., El-Deek, B., Maimani, M. \& El-Desoky, S. Social impact of dialysis on children and their families. Indian. J. Pediatr. 81, 1020-1026 (2014).

207. Alnazly, E. K. Burden and coping strategies among Jordanian caregivers of patients undergoing hemodialysis. Hemodial. Int. 20, 84-93 (2016).

208. Plantinga, L. C. et al. Association of social support with outcomes in incident dialysis patients. Clin. J. Am. Soc. Nephrol. 5, 1480-1488 (2010).
209. Jacquet, S. \& Trinh, E. The potential burden of home dialysis on patients and caregivers: a narrative review. Can. J. Kidney Health Dis. 6, 2054358119893335 (2019).

210. Nataatmadja, M. et al. Quality of life in caregivers of patients randomized to standard- versus extendedhours hemodialysis. Kidney Int. Rep. 6, 1058-1065 (2021).

211. Vanholder, R. et al. Reducing the costs of chronic kidney disease while delivering quality health care: a call to action. Nat. Rev. Nephrol. 13, 393-409 (2017).

212. Klarenbach, S. W., Tonelli, M., Chui, B. \& Manns, B. J. Economic evaluation of dialysis therapies. Nat. Rev. Nephrol. 10, 644-652 (2014).

213. Yeung, E. et al. Current status of health systems financing and oversight for end-stage kidney disease care: a cross-sectional global survey. BMJ Open 11 , e047245 (2021)

214. Antlanger, M. et al. Sex differences in kidney replacement therapy initiation and maintenance. Clin. J. Am. Soc. Nephrol. 14, 1616-1625 (2019).

215. United States Renal Data System. 2016 USRDS Annual Data Report: Epidemiology of kidney disease in the United States. (National Institutes of Health, National Institute of Diabetes and Digestive and Kidney Diseases, Bethesda, MD, 2016).

216. Couchoud, C. et al. From registry data collection to international comparisons: examples of haemodialysis duration and frequency. Nephrol. Dial. Transpl. 24, 217-224 (2009)

217. Noordzij, M. et al. Use of vascular access for haemodialysis in Europe: a report from the ERA-EDTA Registry. Nephrol. Dial. Transpl. 29, 1956-1964 (2014).

218. Caplin, B., Kumar, S. \& Davenport, A. Patients' perspective of haemodialysis-associated symptoms. Nephrol. Dial. Transpl. 26, 2656-2663 (2011)

219. Carrero, J. J., Hecking, M., Chesnaye, N. C. \& Jager, K. J. Sex and gender disparities in the epidemiology and outcomes of chronic kidney disease. Nat. Rev. Nephrol. 14, 151-164 (2018)

220. Kutner, N. G., Zhang, R. \& Brogan, D. Race, gender, and incident dialysis patients' reported health status and quality of life. J. Am. Soc. Nephrol. 16, 1440-1448 (2005)

221. Chan, H. W., Clayton, P. A., McDonald, S. P., Agar, J. W. $\&$ Jose, M. D. Risk factors for dialysis withdrawal: an analysis of the Australia and New Zealand Dialysis and Transplant (ANZDATA) Registry, 1999-2008. Clin. J. Am. Soc. Nephrol. 7, 775-781 (2012).

222. Adams, S. V. et al. Sex differences in hospitalizations with maintenance hemodialysis. J. Am. Soc. Nephrol. 28, 2721-2728 (2017)

223. MacRae, J. M. et al. Sex differences in the vascular access of hemodialysis patients: a cohort study. Clin. Kidney J. 14, 1412-1418 (2021).

224. Miller, C. D., Robbin, M. L. \& Allon, M. Gender differences in outcomes of arteriovenous fistulas in hemodialysis patients. Kidney Int. 63, 346-352 (2003).

225. Hecking M et al Sex-specific differences in hemodialysis prevalence and practices and the male-to-female mortality rate: the Dialysis Outcomes and Practice Patterns Study (DOPPS). PLoS Med. 11, e1001750 (2014).

226. Carrero, J. J. et al. Cardiovascular and noncardiovascular mortality among men and women starting dialysis. Clin. J. Am. Soc. Nephrol. 6, 1722-1730 (2011).

227. Ahearn, P., Johansen, K. L., McCulloch, C. E., Grimes, B. A. \& Ku, E. Sex disparities in risk of mortality among children with ESRD. Am. J. Kidney Dis. 73 156-162 (2019).

228. Depner, T. et al. Dialysis dose and the effect of gender and body size on outcome in the HEMO Study. Kidney Int. 65, 1386-1394 (2004).

229. Spalding, E. M., Chandna, S. M., Davenport, A. \& Farrington, K. Kt/V underestimates the hemodialysis dose in women and small men. Kidney Int. 74, 348-355 (2008)

230. Kurella, M., Covinsky, K. E., Collins, A. J. \& Chertow, G. M. Octogenarians and nonagenarians starting dialysis in the United States. Ann. Intern. Med. 146, 177-183 (2007).

231. Canaud, B. et al. Clinical practices and outcomes in elderly hemodialysis patients: results from the Dialysis Outcomes and Practice Patterns Study (DOPPS). Clin. J. Am. Soc. Nephrol. 6, 1651-1662 (2011)

232. Song, Y. H., Cai, G. Y., Xiao, Y. F. \& Chen, X. M. Risk factors for mortality in elderly haemodialysis patients: a systematic review and meta-analysis. BMC Nephrol. 21, 377 (2020).
233. Malavade, T., Sokwala, A. \& Jassal, S. V. Dialysis therapies in older patients with end-stage renal disease. Clin. Geriatr. Med. 29, 625-639 (2013).

234. Raj, R., Brown, B., Ahuja, K., Frandsen, M. \& Jose, M Enabling good outcomes in older adults on dialysis: a qualitative study. BMC Nephrol. 21, 28 (2020).

235. Jassal, S. V. \& Chow, E. Age-old musings: twenty-first century management of advanced kidney disease in older individuals. Nat. Rev. Nephrol. 18, 1-2 (2022).

236. Ashuntantang, G. et al. Outcomes in adults and children with end-stage kidney disease requiring dialysis in sub-Saharan Africa: a systematic review. Lancet Glob. Health 5, e408-e417 (2017).

237. Halle, M. P. et al. Epidemiology and outcomes of children with renal failure in the pediatric ward of a tertiary hospital in Cameroon. BMC Pediatr. 17, 202 (2017).

238. Rees, L., Schaefer, F., Schmitt, C. P., Shroff, R. $\&$ Warady, B. A. Chronic dialysis in children and adolescents: challenges and outcomes. Lancet Child. Adolesc. Health 1, 68-77 (2017).

239. Chesnaye, N. C. et al. Mortality risk in European children with end-stage renal disease on dialysis. Kidney Int. 89, 1355-1362 (2016).

240. Mitsnefes, M. M., Laskin, B. L., Dahhou, M., Zhang, X $\&$ Foster, B. J. Mortality risk among children initially treated with dialysis for end-stage kidney disease, 1990-2010. JAMA 309, 1921-1929 (2013).

241. McDonald, S. P., Craig, J. C., Australian \& New Zealand Paediatric Nephrology Association Long-term survival of children with end-stage renal disease. N. Engl. J. Med. 350, 2654-2662 (2004).

242. Ferris, M. et al. Hemodialysis outcomes in a global sample of children and young adult hemodialysis patients: the PICCOLO MONDO cohort. Clin. Kidney J. 9, 295-302 (2016).

243. Mekahli, D., Ledermann, S., Gullett, A. \& Rees, L. Evaluation of quality of life by young adult survivors of severe chronic kidney disease in infancy. Pediatr. Nephrol. 29, 1387-1393 (2014).

244. McDonald, S. P. \& Russ, G. R. Current incidence, treatment patterns and outcome of end-stage renal disease among indigenous groups in Australia and New Zealand. Nephrology 8, 42-48 (2003).

245. Narva, A. S. Reducing the burden of chronic kidney disease among American Indians. Adv. Chronic Kidney Dis. 15, 168-173 (2008).

246. McDonald, S. P. Placing Aboriginal kidney disease in context. CMAJ 186, 93-94 (2014)

247. Hughes, J. T. et al. My experiences with kidney care: a qualitative study of adults in the Northern Territory of Australia living with chronic kidney disease, dialysis and transplantation. PLoS One 14, e0225722 (2019).

248. Cass, A., Cunningham, J., Wang, Z. \& Hoy, W. Regiona variation in the incidence of end-stage renal disease in Indigenous Australians. Med. J. Aust. 175, 24-27 (2001).

249. McKercher, C., Chan, H. W., Clayton, P. A McDonald, S. \& Jose, M. D. Dialysis outcomes of elderly Indigenous and non-Indigenous Australians Nephrology 19, 610-616 (2014).

250. McDonald, S. P. \& Russ, G. R. Burden of end-stage renal disease among indigenous peoples in Australia and New Zealand. Kidney Int. Suppl. 63 (Suppl. 83), S123-S127 (2003).

251. Frankenfield, D. L., Roman, S. H., Rocco, M. V., Bedinger, M. R. \& McClellan, W. M. Disparity in outcomes for adult Native American hemodialysis patients? Findings from the ESRD Clinical Performance Measures Project, 1996 to 1999. Kidney Int. 65, 1426-1434 (2004).

252. Burrows, N. R., Cho, P., McKeever Bullard K. Narva, A. S. \& Eggers, P. W. Survival on dialysis among American Indians and Alaska Natives with diabetes in the United States, 1995-2010. Am. J. Public Health 104, S490-S495 (2014).

253. Rumpsfeld, M., Arild, E., Norum, J. \& Breivik, E. Telemedicine in haemodialysis: a university department and two remote satellites linked together as one common workplace. J. Telemed. Telecare 11, 251-255 (2005).

254. Tan, E. Impact of Virtual Clinics and Telehealth Medicine in Rural Nephrology, New Zealand: A Waikato Perspective. (Australian and New Zealand Society of Nephrology, Canberra, Australia, 2015).

255. Hughes, J. T., Lowah, G. \& Kelly, J. Re-framing the Indigenous kidney health workforce. Med. J. Aust 211, 6-6 e 1 (2019)

256. Diamant, M. J. et al. A comparison of quality of life and travel-related factors between in-center and satellite-based hemodialysis patients. Clin. J. Am Soc. Nephrol. 5, 268-274 (2010). 
257. Ovtcharenko N. \& Thomson, B. K. A. Interventions to improve clinical outcomes in indigenous or remote patients with chronic kidney disease: a scoping review. Can. J. Kidney Health Dis. 6, 2054358119887154 (2019).

258. Richels, L. et al. Community-based dialysis in Saskatchewan First Nations: a grassroots approach to gaining insight and perspective from First Nations patients with chronic kidney disease. Can. J. Kidney Health Dis. 7, 2054358120914689 (2020).

259. Marley, J. V. et al. Haemodialysis outcomes of Aboriginal and Torres Strait Islander patients of remote Kimberley region origin. Med. J. Aust. 193, 516-520 (2010).

260. See, E. J. et al. Availability, coverage, and scope of health information systems for kidney care across world countries and regions. Nephrol. Dial. Transplant. 37, 159-167 (2020)

261. Kliger, A. S. Quality measures for dialysis: time for a balanced scorecard. Clin. J. Am. Soc. Nephrol. 11 363-368 (2016)

262. Breckenridge, K. et al. How to routinely collect data on patient-reported outcome and experience measures in renal registries in Europe: an expert consensus meeting Nephrol. Dial. Transpl. 30 1605-1614 (2015)

263. Tong, A. et al. Implementing core outcomes in kidney disease: report of the Standardized Outcomes in Nephrology (SONG) implementation workshop.

Kidney Int. 94, 1053-1068 (2018)

Acknowledgements

D.W.J. is a current recipient of an Australian National Health and Medical Research Council Leadership Investigator Grant. We thank Ghenette Houston and Sophanny Tiv of the Kidney Health Research Group, University of Alberta, for administrative and technical support.

Author contributions

All authors researched data for the article, made substantial contributions to discussions of the content and wrote, reviewed or edited the manuscript before submission.

\section{Competing interests}

V.J. has received fees from AstraZeneca, NephroPlus and Zydus Cadilla, and grants from Baxter Healthcare, Biocon and GlaxoSmithKline; all funds are paid to his organization D.W.J. has received consultancy fees, research grants, speaker's honoraria and travel sponsorships from Baxter Healthcare and Fresenius Medical Care, consultancy fees from Astra Zeneca, Bayer and AWAK, speaker's honoraria from ONO and $\mathrm{BI} \&$ Lilly, and travel sponsorships from Ono and Amgen. The other authors declare no competing interests.

Peer review information

Nature Reviews Nephrology thanks J. Burton, M.-Y. Chothia, M.R. Davids and V. Stel for their contribution to the peer review of this work.

Publisher's note

Springer Nature remains neutral with regard to jurisdictional claims in published maps and institutional affiliations.

\section{Supplementary information}

The online version contains supplementary material available at https://doi.org/10.1038/s41581-022-00542-7.

\section{RELATED LINKS}

Kidney Health Initiative: https://khi.asn-online.org

Standardized Outcomes in Nephrology in HD (SONG-HD)

initiative: https://songinitiative.org/projects/song-hd/

(c) Springer Nature Limited 2022 